\title{
LAS TRANSFORMACIONES INSTITUCIONALES EN LA ADMINISTRACIÓN HACENDARIA DE BRASIL: DE LA COLONIA A LA NACIÓN, SIGLOS XVIII-XIX
}

\author{
INSTITUTIONAL TRANSFORMATIONS \\ IN THE TREASURY ADMINISTRATION OF BRAZIL: \\ FROM THE COLONY TO THE NATION, \\ 18TH-19TH CENTURIES
}

\author{
BRUNO AIDAR \\ Universidad Federal de Alfenas, Instituto de Ciencias Sociales Aplicadas, \\ Brasil \\ profbrunoaidar@gmail.com \\ Cláudia Chaves \\ Universidad Federal de Ouro Preto, Instituto de Ciencias Humanas \\ y Sociales, Brasil \\ claudia.chaves@ufop.edu.br \\ Marcia EcKert Miranda \\ Universidad Federal de São Paulo, Escuela de Filosofía, Letras \\ y Ciencias Humanas, Brasil \\ mmiranda@unifesp.br
}

https://doi.org/10.36105/iut.2021n33.03

Recibido: 01/08/2021

Aceptado: 30/08/2021

\section{RESUMEN}

Desde la creación del Erario Regio, a fines de 1761, hasta mediados del siglo XIX, cuando se realizaron las últimas reformas institucionales importantes en Brasil como un imperio independiente, la transformación de la administración hacendaria 
colonial en una nacional implicó distintas significaciones y reorientaciones de las diferentes capas que comprendían la recepción de ingresos y la gestión de la Real Hacienda y, después, del tesoro público. Lejos de estar compuesto por un único polo extractivo en medio a una uniformidad administrativa, como podría suponerse por una genealogía del Tesoro Nacional al Erario Regio, la recaudación de impuestos requería trabajar en diferentes niveles arquitectónicos de un Estado colonial y, más tarde, nacional. Este texto busca resaltar los elementos principales de esta larga transición conceptual e institucional de la administración hacendaria en Brasil desde la época de las reformas del marqués de Pombal hasta mediados del siglo XIX.

\section{Palabras clave:}

Erario Regio, Tesoro nacional, Reformas pombalinas, administración fiscal, impuestos liberales.

\section{Abstract:}

Since the creation of the Royal Treasury at the end of 1761, until mid-nineteenth century, when the last important institutional reforms in Brazil as an independent empire were carried out, the transformation of a colonial treasury administration into a national one implied different meanings and reorientations of the different layers that covered aspects such as the reception of income and the management of the Royal Treasury and later, of the Public Treasury. Far from being composed of a single extractive pole during an administrative uniformity, as it might be inferred from tracing the genealogy of the Royal Treasury into the National Treasury, the collection of taxes at the different socioeconomic levels of a Colonial State, and later, a National State, required improvements. This paper strives to highlight the main elements of this lengthy conceptual and institutional transition of Brazil's treasury administration since the times of the Marquis of Pombal's reforms until the mid-nineteenth century.

Keywords:

Royal Treasury, National Treasury, Pombaline Reforms, fiscal administration, liberal taxes.

\section{LAS PALABRAS Y EL FISCO: DE LA REAL HACIENDA AL TESORO PÚBLICO}

De inicio, se puede establecer una gran división entre el mundo ibérico y el universo anglo-francés que tiene sus raíces en el período medieval y atraviesa todo el proceso de formación de los Estados modernos, sobre el término general de referencia para la gestión de los bienes del Estado. El amplio uso ibérico de los términos Fazenda/Hacienda Real y, en menor medida, Erário/Erario difiere 
del mayor uso francés de los términos Finances y Trésor Royal, un aspecto observado por Bluteau que notó el galicismo del sustantivo finanzas. ${ }^{1}$ En inglés, se observa una influencia normanda en el uso de los términos Exchequer y Treasury, generalizados en los siglos XIV y XV. ${ }^{2}$

A principios del siglo XVIII, Bluteau definió Fazenda como "riqueza, dinero, capital" y también, en un sentido restringido, "bienes raíces, tierras, haciendas". 3 La idea de Hacienda real se refería a la riqueza perteneciente y destinada al rey. La Fazenda Real sería "el dinero, que proviene de las sisas, alcabalas, y tributos, que se pagan al príncipe". ${ }^{4} \mathrm{El}$ diccionario de castellano, contemporáneo a la obra portuguesa, indicaba hacienda además del significado de los "bienes, posesiones y riquezas que uno tiene", las tierras del campo, el trabajo doméstico y los negocios entre dos personas. ${ }^{5}$

De origen latino, la definición de Erario (AErarium) estaba más cerca del sentido físico, el lugar donde se depositaba el dinero público. ${ }^{6}$ En la época romana hubo diferentes erarios: imperatorio, militar, público y privado, reservándose al primero "el dinero de las imposiciones, y tributos". Sin embargo, en la definición de Bluteau, la dimensión real y la dimensión pública son equiparadas en el término erario: "Tesoro real, tesoro público". ${ }^{7}$ Entre tanto, este enfoque es bastante claro: "erario, o tesoro del príncipe, es decir, el dinero de impuestos, tributos, sisas, fintas, décimos etc.". 8 A su vez, en castellano, el término "Erario" resaltó el sentido público de los recursos y la posibilidad de otras formas de gobierno: "El thesóro público del reino ù república, ò el lugar donde se recoge y guarda el dinero del público". 9

La Hacienda Regia fue considerada una extensión de la persona real en la cual los intereses de los vasallos eran contemplados por las ideas del bien común. Según António Manuel Hespanha: "la riqueza del rey no era un bien superior o incluso separable de la riqueza del reino, entendida como la suma de la riqueza de los súbditos". ${ }^{10}$ A su vez, en 1592, la creación del Consejo de Hacienda era justificado por las "necesidades de mi hacienda [del rey] van siempre creciendo, y cada vez faltan más cosas importantes, necesarias para mi servicio, y el bien común de mi estados y vasallos". ${ }^{11}$ Los veedores de hacienda, una posición creada en el siglo XIV, ${ }^{12}$ y cuyas funciones fueron absorbidas por el Consejo de

\footnotetext{
Bluteau, Raphael, Vocabulario portuguez, 1712-1728, vol. 9, p. 430.

Online Etymology Dictionary, <http://www.etymonline.com/index.php>. [Consulta: 24 de agosto de 2017].

Bluteau, Raphael, Vocabulario portuguez, 1712-1728, vol. 4, p. 48.

Ibidem, vol. 9, p. 430.

Real Academia Española, Diccionario de la lengua, 1726-1739, vol. 4, p. 120.

BluteaU, Raphael, Vocabulario portuguez, 1712-1728, vol. 8, p. 156.

Ibidem, vol. 3, p. 187.

Ibidem, vol. 4, p. 132.

Real Academia Española, Diccionario de la lengua, 1726-1739, vol. 3, p. 543.

Hespanha, António Manuel, “A fazenda”, 1998, p. 182.

11 SousA, José Roberto Monteiro de Campos Coelho e, Systema, ou collecção, 1783-1791, vol. 1, p. 162.

12 La publicación del regimiento de los "veedores de Hacienda", sin embargo, solo tuvo lugar en 1516 y demostró la tendencia de reunir la información hacendaria del reino y los dominios ultramarinos a través de la Casa de India (Hespanha, António Manuel, "A fazenda", 1998).
} 
Hacienda, deberían "cuidar de todas las cosas que pertenecen a nuestro servicio, principalmente en las cosas de nuestra hacienda", y "cobrar nuestras rentas, y todos nuestros derechos, tributos y cosas que nos pertenecen, que tenemos en nuestros reinos y señoríos, y fuera de ellos". ${ }^{13}$ Por lo tanto, este contexto puede entenderse como el punto de partida de una administración hacendaria más organizada y centralizada. El consejo, dividido en reparticiones y que también involucraba las conquistas, debía administrar los rendimientos, supervisar el comercio e inspeccionar las aduanas, la Casa de los Cuentos y la Casa de India. Ni siquiera la creación del Consejo Ultramarino (1642) eliminó del Consejo de Hacienda el control de las rentas ultramarinas. ${ }^{14}$ Además, también es cierto que el propio desarrollo de la monarquía portuguesa en el pilar de los descubrimientos en el extranjero desde el siglo xv, el epíteto real "señor de Guinea y de la conquista, navegación y comercio de Etiopía, Arabia, Persia e India" contribuyó a esta organización. La reiteración del pronombre posesivo, a partir de entonces intensificado, explica el sentido de dominio ejercido por el rey. Como señaló acertadamente Alexandre Herculano, la idea de que "el comercio obtenido a través de las conquistas y navegaciones pertenecía al señorío real"15 entrelazaba el poder real a las conquistas por los hilos del comercio y las finanzas imperiales.

A mediados del siglo XVIII, el surgimiento de un modelo político absolutista, expresado entre otros aspectos por la creación de Erario Regio, implicaría una visión más abstracta de la administración hacendaria. Con su aparición, la Casa de los Cuentos fue eliminada y el nuevo organismo comenzó a concentrar todo el control económico de las rentas de la monarquía. Junto con esta creación, el Consejo de Hacienda experimentó cambios profundos. Entre ellos estaba la reanudación del control de la jurisdicción contenciosa de la administración hacendaria, perdida para la Casa de Suplicación a principios del siglo XVII. La creación del nuevo orden fiscal se justificó por el carácter esencial de la "recaudación regular y exacta de rentas, que constituían el Erario público" para "el establecimiento, la conservación y el aumento de las monarquías". Según la carta de creación del Erario Regio, tales ingresos permitirían no solo sostener el esplendor de la autoridad real, sino también ministros, militares, propietarios de estándares de interés y receptores de tenencias y misericordias. ${ }^{16}$ Todos estos gastos fueron considerados "causas públicas y urgentes" dotados de "necesidad indispensable" establecida por la dimensión de la policía del gobierno:

[...] desde que hubo una Policía, se establecieron las Leyes de todas las naciones del mundo (antiguas y modernas), los exuberantes privilegios del fisco, o Erario, que, al llamarse Regio, es en realidad público y común, porque depende no solo de la conservación de la monarquía en general; pero incluso el diario de alimentos de cada uno de los Estados, y sus principales personas en particular [...]. ${ }^{17}$

13 Sousa, José Roberto Monteiro de Campos Coelho e, Systema, ou collecção, 1783-1791, vol. 1, pp. 1-2.

14 Salgado, Graça (coord.), Fiscais e meirinhos, 1985.

15 Herculano, Alexandre, Opúsculos, s. a., vol. 5, p. 25.

16 Sousa, José Roberto Monteiro de Campos Coelho e, Systema, ou collecção, 1783-1791, vol. 3, p. 451.

17 Ibidem, p. 452. 
La cita apunta el ideal de integración simbiótica entre los intereses reales y los generales a través del flujo de gastos realizados por el Estado. Si la dimensión de la centralización de los ingresos es un aspecto importante de la creación del Erario Regio, no conviene subestimar el proceso de mejor distribución de gastos, llegando a una buena parte de la población, incluso en una visión jerárquica y estamental de la sociedad del antiguo régimen. Otro aspecto notable es la distinción entre príncipe y monarquía. La Hacienda Real pasa a ser vista como parte del gobierno monárquico en lugar de una simple extensión de los bienes del rey.

Esta perspectiva sería reformulada nuevamente con la crisis de los estados absolutistas y el advenimiento del constitucionalismo. En Portugal, con la revolución de 1820 (vintista), la construcción del sistema constitucional traería reformulaciones al antiguo concepto de Real Hacienda. En este sentido, la contribución de José Ferreira Borges sería notable: "La ciencia de los impuestos y gastos de un estado carecía de un nombre científico. El nombre Fazenda por sí solo no designa a la ciencia, y el epíteto real no se ajusta a los ingresos públicos de una nación libre. Hoy ni el rey tiene el señorío de la nación, ni el tributo es un signo de vasallaje". ${ }^{18}$ El término finanzas sería nuevo, una rama derivada de la economía política, similar al uso portugués de Tesoro o Erario. Ferreira Borges propone entonces un nuevo término, acuñado del griego, la sintelología, que sería la ciencia de las contribuciones y los gastos, de una manera más simple, o la "ciencia que enseña los medios para satisfacer las necesidades del estado político con los recursos del estado social". ${ }^{19} \mathrm{El}$ neologismo tendría un significado más preciso y específico que finanzas y hacienda, aunque el autor no abandonó el uso de las últimas palabras. Es importante destacar la intención de un enfoque científico y la organización de un cuerpo de doctrinas dedicadas a estos asuntos.

Además de la economía política, también hubo los primeros intentos de pensar legalmente sobre la administración hacendaria. Un ejemplo que refleja estos intentos es el libro de Pascoal de Mello Freire, Instituciones de derecho civil portugués (1805), en el que analiza las instituciones hacendarias y la fiscalidad dentro de una perspectiva jurídica. Unos años más tarde, la obra Compendio de derecho financiero (1841), de José Antônio da Silva Maia, ampliado más tarde por José Maurício Fernandes Pereira de Barros se convertiría en una referencia importante para este mismo campo. ${ }^{20}$ Para Silva Maia, era necesario establecer una rama, llamada derecho financiero, responsable del estudio de "las reglas, por qué se debe dirigir la administración general de la Hacienda Nacional, con respecto a los ingresos y gastos del Imperio, la recaudación, la inspección y distribución de los recursos públicos". ${ }^{21}$ Este campo también debía ser responsable de supervisar el cuerpo de funcionarios responsables de recaudar y usar los recursos públicos. Dichas perspectivas, en el Brasil ya independiente, dieron como resultado la formulación de órganos como el Tribunal del Tesoro Público Nacional,

18 Borges, José Ferreira, Principios de syntelologia, 1831, p. 3, cursivas originales.

19 Ibidem, p. v.

20 Barros, José Mauricio Fernandes Pereira de, Apontamentos de direito, 1855.

21 MaIA, José Antônio da Silva, Compendio do direito, 1841, p. 1. 
sucesor del Consejo de Hacienda, instituido por la Ley del 4 de octubre de 1831 y que tenía como principales atribuciones la "dirección e inspección de los ingresos y gastos nacionales, inspeccionar la recaudación, distribución y contabilidad de todos los ingresos públicos y decidir todos los asuntos administrativos". ${ }^{22}$

Si el derecho financiero era responsable de la organización de las reglas, la función activa de ejercer el poder administrativo, fiscalizar y administrar los ingresos y gastos públicos quedaba a cargo del Tesoro Nacional. Para ejercer esta función, los pilares de la administración hacendaria se basaron en la búsqueda de "racionalidad y simplicidad" en las operaciones vinculadas a los ingresos y gastos públicos, así como "la regular y adecuada publicidad de los resultados de estas". ${ }^{23}$ En este punto, se puede notar una distinción con respecto de las reformas hacendarias absolutistas emprendidas por Pombal. En el régimen constitucional, la dimensión pública de centralizar la información se convierte en la piedra angular que diferencia el "sistema de secreto" que dominó la antigua administración hacendaria, siendo un crimen de Estado revelar información fiscal. ${ }^{24} \mathrm{La}$ "publicidad obligatoria" era un hecho nuevo, que estaba de acuerdo con los principios de representatividad liberal, ya que dependía de los "representantes de la nación" examinar adecuadamente estas cuentas, de esta manera articulando, el Ejecutivo y el Legislativo en la gestión de las finanzas del Estado. ${ }^{25}$

Hubo muchas dificultades en la aplicación del principio de publicidad y supervisión de cuentas por parte del Legislativo, hasta el punto de que, incluso en 1857, Pimenta Bueno defendió la creación urgente de un tribunal de cuentas, "que examine y compare la fidelidad de los gastos con los créditos votados, los ingresos con las leyes del impuesto, que analiza y sigue el testimonio de documentos auténticos en todos sus movimientos la aplicación y el uso de los valores del Estado", asegurando "la realidad y la legalidad de las cuentas". ${ }^{26}$ Aunque una institución con esta designación, tribunal de cuentas, siempre se había requerido durante todo el siglo XIX, solo se creó al comienzo de la República, en 1890. Sin embargo, como mencionamos anteriormente, el Tribunal del Tesoro Público Nacional en 1831 ya había absorbido las funciones del entonces extinto Consejo de Hacienda. Su constitución era entonces colegiada y su papel, más consultivo de lo esperado por varios políticos del Imperio, que se encontraban insatisfechos con las reformas financieras llevadas a cabo en la década de 1850. En este sentido, todavía, el Decreto núm. 2343 de 1859, tenía como objetivo reforzar el papel de la Corte como un organismo que realmente inspeccionara las cuentas públicas, como los pagos y la aplicación de multas.

Al comienzo del período republicano, la obra Elementos de Finanzas (1896) de Amaro Cavalcanti registraría la influencia de los tratados de finanzas públicas

\footnotetext{
22 Ley del 4 de octubre de 1831, Art. 6 §1. Para todas las leyes y decretos del periodo imperial citadas en este texto véase Collecção das leis, 1822-1889. 
alemanes y franceses. Para el autor, la administración financiera era definida como "la parte de la administración pública, que se ocupa de la economía del Estado o, en otras palabras, que tiene por objeto la provisión de medios económicos (bienes, rentas públicas) y el uso de estos medios (gasto público) para los fines del Estado". ${ }^{27}$ Además, la administración financiera también incluyó la organización de los funcionarios hacendarios y las relaciones jurídicas entre particulares y el Estado. ${ }^{28}$ La definición de Cavalcanti muestra una preocupación por la racionalidad instrumental en el uso de los recursos públicos, tomándose como natural la dimensión pública de los ingresos y gastos del Estado. Desde el punto de vista de la delimitación entre el espacio público y el espacio real en la administración hacendaria, la República no se encontró con las dificultades que enfrentaron los constructores del país independiente, lo que se sumó a los esfuerzos del siglo XIX en la construcción de una identidad entre el Estado y las finanzas públicas, disociándola de la antigua Real Hacienda.

\section{EL PLAN DE LA ADMINISTRACIÓN CENTRAL: DEL ERARIO REGIO AL TESORO NACIONAL}

El reinado de D. José I estuvo marcado por intensas reformas en la estructura y las prácticas administrativas en la esfera hacendaria, ${ }^{29}$ motivadas por la caída de la producción de oro y los desafíos de reorganizar la administración después del terremoto de 1755, consolidando la transición desde un concepto de administración doméstica para una administración política, regida por el interés público. ${ }^{30}$ Dado que la recaudación de impuestos y la recepción de rentas reales eran áreas privilegiadas para aumentar el poder de la corona y un requisito para la revitalización económica, estas reformas, lideradas por el conde de Oeiras, futuro marqués de Pombal, se basaron en el control del Tesoro, articulando los diferentes espacios que conformaron el Imperio portugués.

El centro de este proceso fue la creación del Erario Regio por el alvará (Real Cédula) del 22 de diciembre de 1761, con el propósito de resolver las superposiciones y ambivalencias, bien cómo aumentar el control y la vigilancia sobre la recaudación de rentas e impuestos, gastos y negocios reales, superando la rutina impuesta por la “(...) división, y la laceración de sus arrendamientos separados en muchas, y muy diferentes ramas, y en muchas, y muy diversas divisiones, solo sirvieron para aniquilarlos, evaporando toda su fuerza sin importar cuánto fueran" (alvará de 22 de diciembre de 1761). Por lo tanto, la creación de este organismo implicó no solo un cambio en la estructura administrativa, sino también en los

27 Cavalcanti, Amaro, Elementos de finanças, 1896, p. 435.

28 Ibidem, p. 436.

29 Entre ellos, los promovidos por el alvará del 21 de mayo de 1751, con la creación de una junta para la Administración de Depósitos Públicos de la Corte y Ciudad de Lisboa para reemplazar los antiguos oficios de los depositarios y las derivadas del alvará del 13 de enero de 1757, que extinguió el Juicio de India y Mina, la Defensoría del Pueblo de la Aduana, las Capillas de la Corona, el Saque de la Moneda, entre otros (Subtil, "Governo e administração", 1998).

30 Subtil, José, "Governo e administração”, 1998, y Barcelos, Fábio Campos, A Secretaria de Estado, 2014. 
procedimientos y poderes de las diferentes instancias de la administración hacendaria en el Reino y en las posesiones ultramarinas.

El conde de Oeiras fue el primer presidente e inspector general del Erario Regio y era asesorado por un tesorero jefe, responsable por la Tesorería General. Los gastos fueron controlados por tres tesoreros: uno para pensiones (tenças), otro para intereses y un tercero para sueldos. Los ingresos estuvieron a cargo de cuatro contadurías, cada uno encabezado por un contador general: $1^{\text {a }}$ Contaduría responsable de la recaudación de los agentes, proveedores, jueces, depósitos, tesoreros, receptores y rematantes de rentas de la Corte y provincia de Extremadura; $2^{\text {a }}$ Contaduría a cargo del departamento de contabilidad responsable de la recaudación en el Reino y las islas de los Azores y Madeira; $3^{\text {a }}$ Contaduría para África, Maranhão y Bahía, y; $4^{\mathrm{a}}$ Contaduría para Río de Janeiro, África Oriental y Asia.

El alvará del 22 de diciembre de 1761 implicó no solo un cambio en la estructura de la administración hacendaria, sino también cambios significativos en el proceso administrativo, en el método de contabilidad y en la producción y el flujo de documentos. En el Erario Regio, las decisiones comenzaron a ser enviadas directamente por su presidente, quien tenía acceso directo al rey, superando la rutina de consulta de los tribunales y consejos. La contabilidad mercantil, o método de partida doble, permitió un control más preciso de los ingresos y su destino, además de permitir el cálculo del saldo en cualquier momento. La estandarización de los libros de registro (diario, libro maestro y libros auxiliares) ayudó en el control y la circulación de la información contable que debería fluir de las tesorerías a los contadores, y de éstos al inspector general del Tesoro. ${ }^{31} \mathrm{Su}$ bordinado al Erario Regio, fueron creadas Juntas de Hacienda que ejercían, en las diferentes ubicaciones del imperio, las funciones relacionadas con la recaudación y el control de los ingresos, así como el control y ejecución del gasto. Otra carta real de la misma fecha reestructuró el Consejo de Hacienda ${ }^{32}$ Aunque autónomos, este organismo y el Erario Regio comenzaron a centralizar todos los asuntos relacionados con la Hacienda. ${ }^{33}$

La centralidad del Erario Regio en materia hacendaria fue confirmada por el alvará del 14 de octubre de 1788, durante el reinado de D. María I, quien determinó que su presidente e inspector general, "Magistrado Supremo de Finanzas",

31 SubTIL, José, "Governo e administração", 1998.

32 El Consejo de Hacienda había sido creado por el reglamento del 20 de noviembre de 1591, durante la Unión Ibérica, y era responsable de la dirección de las finanzas del Reino, estando subordinado, entre otros, a Casa de los Cuentos, la Casa de India, la Casa de la Moneda, aduanas (BArcelos, Fábio Campos, A Secretaria de Estado, 2014). Su creación implicó la transferencia de jurisdicción de los veedores a un órgano colegiado, formado por un veedor de Hacienda, que se desempeñó como presidente del Consejo, y cuatro concejeros. Inicialmente, el Consejo tenía jurisdicción voluntaria y la jurisdicción contenciosa recaía al Juicio de los Actos de Hacienda (Juizo dos Feitos de Fazenda). Con el tiempo, esta división de jurisdicciones cambió, convirtiéndose en exclusiva para el Consejo de Hacienda desde 1761. Sin embargo, mientras fortaleció la competencia judicial, el Consejo de Hacienda perdió su papel en la gestión del área hacendaria, asumido por el Erario Regio (Conselho de Fazenda, 1995).

33 Conselho de Fazenda, 1995. 
tendría el título de ministro de Estado, ${ }^{34}$ y por el alvará de 17 de diciembre de 1790 que estableció una reorganización jerárquica de los órganos hacendarios centrales promoviendo la unión del Consejo de Hacienda y del Real Erario. Así, el presidente del Consejo de Hacienda pasó a ser, al mismo tiempo, presidente del Real Erario y ministro de Estado de la división de Hacienda. Este vínculo fue cambiado después del establecimiento de la Corte en Brasil. Mediante el decreto del 11 de marzo de 1808, el Príncipe Regente, D. João determinó que el presidente del Erario Regio creado en Río de Janeiro fuera el secretario de Estado de Negocios de Brasil, puesto que no se había creado nuevamente la Secretaría de Estado de Negocios de Hacienda, que mantuvo su funcionamiento regular en Lisboa. ${ }^{35}$

Según el alvará del 28 de junio de 1808, el Erario Regio o Tesoro Público de Río de Janeiro, así como el Consejo de Hacienda, tenían las mismas prerrogativas que la sucursal de Lisboa, según lo establecido en la Carta Regia de 1761. Se trataba en la esencia de la duplicación de estos organismos, ya que los de Lisboa continuaron operando, incluso con jurisdicciones territoriales alteradas.

El Erario Regio de Río de Janeiro estaba compuesto por un presidente, un tesorero jefe, un registrador de los ingresos, un procurador de hacienda, un contador general y tres contadurías generales. La primera contaduría fue responsable de recolectar, inspeccionar y registrar los ingresos de la ciudad y provincia de Río de Janeiro; la segunda, para rentas y contratos de África oriental, Asia portuguesa, Minas Gerais, São Paulo, Goiás, Mato Grosso y Rio Grande do Sul; y la tercera, para ingresos y contratos de Bahía, Pernambuco, Maranhão, Pará, Ceará, Piauí, Paraíba, Islas de Cabo Verde, Azores, Madeira y África Occidental. Como resultado de la creación del Erario Regio, se extinguió la Junta de Hacienda y Revisión de la Capitanía de Río de Janeiro. ${ }^{36}$ Se mantuvo la práctica de despacho directo del presidente del Real Erario con el monarca, a quien debía presentar al final de cada año la cuenta general del estado de la hacienda.

El Consejo de Hacienda, a pesar de mantener los deberes del que todavía existía en Portugal, amplió sus funciones, pasando a su jurisdicción los territorios de las colonias de ultramar, como Azores, Madeira, Cabo Verde, Santo Tomé y dominios en África y Asia, que anteriormente eran competencia del Consejo Ultramarino. Era compuesto por su presidente, que ocupaba el cargo de presidente del Real Erario, dos consejeros nombrados por el Rey y varios funcionarios. El Consejo de Hacienda en Lisboa mantuvo su funcionamiento, sin embargo, su jurisdicción solo abarcaba el territorio europeo. Aunque formalmente autónomo, la práctica demostró la existencia de una jerarquía entre estos tribunales, ya que, como señaló Eder Ribeiro, el Consejo de Hacienda de Río de Janeiro actuó como

\footnotetext{
34 A pesar de que se creó el cargo de ministro de Hacienda, la Secretaría de Estado de Negocios de Hacienda solo comenzó a funcionar en enero de 1801. Por lo tanto, la creación del cargo de secretario precedió a la secretaría efectivamente instalada cuando fue asumida por D. Rodrigo de Souza Coutinho (MARTINs, Ana Canas Delgado, Governação e arquivos, 2007, y BARcelos, Fábio Campos, A Secretaria de Estado, 2014).

36 Barcelos, Fábio Campos, A Secretaria de Estado, 2014.
} 
última instancia en los asuntos que involucraban intereses que cubrían más de un territorio del imperio portugués, señalando la resignificación entre el nuevo centro y las partes fiscales del imperio, un proceso que no ocurrió sin conflictos. ${ }^{37}$

Progresivamente, la extinción de algunos órganos y oficinas llevó a la ampliación de los poderes del Erario Regio con la creación de la Administración de Extracción de Diamantes, o Dirección General de Diamantes y Junta de la Dirección General de la Real Extracción de Diamantes (Decreto del 5 de septiembre de 1808), la absorción de funciones relativas a la recaudación de impuestos del aguardiente, venta de sal, contratos de tabaco y derechos de esclavos, previamente ejercidos por la Mesa de Inspección de Río de Janeiro (alvará del 3 de junio de 1809), así como sobre la recaudación de los rendimientos de la carne fresca, pesca y otros creados en Brasil (alvará del 17 de agosto de 1809). La creación y el funcionamiento de los órganos centrales de la estructura hacendaria en Brasil no solo desplazaron la celebración de contratos reales al espacio colonial, sino que también fortalecieron la posición de la élite económica con las autoridades hacendarias, ya sea en la Corte o en las capitanías a través de las Juntas de Hacienda.

En vísperas del nombramiento de D. Pedro Regente do Brasil y anunciando su regreso a Portugal (Decreto del 7 de marzo de 1821), D. João VI firmó el decreto del 6 de marzo de 1821 que creó el cargo de Ministro y Secretario de Negocios de Hacienda separado del Secretario de Estado de Negocios en Brasil, nominando para servir como ministro y presidente del Real Erario a D. Diogo Menezes, conde de Louzã. Aunque, como señaló Barcelos, este hecho no implicaba la instalación efectiva de esta Secretaría de Estado, fue este secretario quien informó, por decisión del 20 de septiembre de 1821, que el Príncipe Regente, "queriendo promover en el Reino de Brasil la adopción de todas las fórmulas del sistema constitucional", determinó que el Erario Regio pasó a llamarse "Hacienda Pública de Río de Janeiro", y que la expresión Hacienda Real fuese remplazada por Hacienda Pública (Decisión núm. 61, de 20 de septiembre 1821). ${ }^{38}$

La disputa por el control de las instituciones centrales marcó el período anterior a la independencia política brasileña. Mediante los Decretos del 29 de septiembre de $1821,{ }^{39}$ las Cortes, con el objetivo de eliminar los poderes del Príncipe Regente de Brasil, determinaron el establecimiento de juntas provisionales en las provincias, concentrando el poder militar en manos de los gobernadores de armas directamente subordinados a Lisboa y ordenaron el regreso de D. Pedro a Portugal. En un intento por reducir los poderes de las instituciones con sede en Brasil, restableciendo la centralidad de los tribunales y otros órganos administrativos ubicados en Lisboa, a través de la Ley del 18 de enero de 1822, se determinó la extinción de todos los tribunales creados en Río de Janeiro, ${ }^{40}$ incluyendo la

37 RibeIro, Eder da Silva, "Nas tramas da política", 2017.

38 Barcelos, Fábio Campos, A Secretaria de Estado, 2014.

39 Decretos publicados con la fecha del 1 de octubre de 1821, pero que solo se conocieron en Brasil a partir de diciembre del mismo año.

40 Entre otras determinaciones, la ley preveía, además de la extinción del Erario Regio, que "Todos los negocios contenciosos, que fueron administrados por el Consejo de Hacienda y la Junta de Comercio, se devuelven al 
Casa de Suplicación, la Mesa del Desembargo del Palacio, la Mesa de Consciencia y Órdenes, el Erario Regio y el Consejo de Hacienda.

Sin embargo, la permanencia del príncipe regente y la desobediencia de las órdenes de Lisboa llevaron al mantenimiento de estas instituciones. En los primeros años posteriores a la independencia, no hubo cambios en la estructura y las rutinas de los órganos hacendarios. Por lo tanto, a pesar del cambio en la nomenclatura alterado por el artículo 170 de la Constitución de 1824, que estableció como órgano central, a cargo de la administración, recaudación y contabilidad, un tribunal llamado Tesoro Nacional (capítulo III, artículo 170), la primera reforma significativa solamente tuvo lugar en la Regencia en $1831 .{ }^{41}$ Esta reforma, como las otras en el período, tuvo su singularidad como resultado del "esfuerzo por conciliar el peso del legado de la administración portuguesa y las ideas liberales". ${ }^{42}$

La Ley del 4 de octubre de 1831 que creó el Tribunal del Tesoro Público Nacional estableció no solo la reforma del organismo central, sino también la de los organismos hacendarios provinciales (tesorerías provinciales) y demarcó la relación entre estos dos organismos. ${ }^{43}$ Este era un órgano colegiado compuesto por un presidente, un inspector general, un contador general y un procurador fiscal, designado por el Emperador. Su presidente sería el ministro y secretario de Estado de Negocios de Hacienda y él era el único con un voto deliberativo. Además, dependía al Tesoro administrar e inspeccionar los ingresos y gastos nacionales, la administración de los bienes nacionales, el cuidado sobre el uso de los recursos públicos, proponer condiciones para tomar prestamos en el país y en el extranjero, fijar y proceder el detalle de los contratos en la Corte y la provincia de Río de Janeiro. El Consejo de Hacienda se extinguió, pasando la jurisdicción voluntaria al Tribunal del Tesoro Nacional en asuntos relacionados con calificaciones de nobleza, sueldos, tenencias, y pensiones, del asentamiento de los bienes nacionales, los contratos de rentas públicas y la emisión de títulos y diplomas a los funcionarios de la Hacienda. La jurisdicción contenciosa se convirtió

tribunal (Relação) de distrito, a excepción de los deberes de la Mesa de Inspección”. Véase la ley del 18 de enero de 1822 que extinguió los tribunales creados en Río de Janeiro y establece la forma de administración de las provincias de Brasil.

41 Esto no quiere decir que la discusión sobre los cambios necesarios en la estructura hacendaria no haya tenido lugar, así como pequeños cambios debido a las dificultades financieras del nuevo Estado y que pretendían establecer un mejor control y centralización del proceso de recaudación de derechos e rentas, como la creación de la Administración de Diversas Rentas (Decreto del 4 de febrero de 1823), la extinción de las Mesas de Inspección (Ley del 5 de noviembre de 1827), la extinción del Tribunal da Bula Cruzada (Ley del 20 de septiembre de 1828), la extinción de los departamentos de muertos y ausentes (Ley del 3 de noviembre de 1830) y de las juntas de recaudación de la décima urbana (Ley de 27 de agosto de 1830). Asimismo, el mantenimiento del propio Consejo de Hacienda fue objeto de discusión, con propuestas para su extinción, como un proyecto presentado por Bernardo Pereira de Vasconcelos a la Cámara de Diputados en 1827, señalando que las atribuciones del Consejo de Hacienda se distribuirían entre los jueces territoriales, las relaciones y el tesoro público. Al ser aprobado en la Cámara de Diputados, su discusión se pospuso en el Senado, y debió reanudarse cuando se discutió la nueva ley del Tesoro (VASCONCELOS, Bernardo Pereira de, "Carta aos senhores", 1999, p. 114).

42 CAmargo, Angelica Ricci, "Juntas da Real Fazenda”, 2013, p. 13.

43 Son pocos los trabajos que abordan esta reforma. Entre los cuales se destacan BuEsCu, Mircea, Organização e administração, 1984 y AIDAR, Bruno, “A reforma do Tesouro”, 2016. 
en responsabilidad de los jueces territoriales. La Tesorería General era la división ejecutiva, a cargo de recolectar y distribuir las sobras de las tesorerías provinciales y otros ingresos que no fueron recaudados por ellos. Las Juntas de Hacienda se extinguieron, reemplazadas por los tesoros provinciales. Estas oficinas, directamente subordinadas al Tesoro Nacional, eran responsables de la administración, recaudación, distribución, contabilidad e inspección de los ingresos públicos en cada provincia. En enero de 1832, se instaló el Tribunal del Tesoro Nacional, siendo su presidente Bernardo Pereira de Vasconcelos. ${ }^{44}$

A lo largo de las décadas de 1830 y 1840, con respecto a la Secretaría de Estado de Hacienda, las reformas se caracterizaron por su carácter innovador frente a otros sectores de la burocracia, al establecer un modelo piramidal más complejo, con el mayor número de empleados y cargos. ${ }^{45}$ Sin embargo, las dificultades administrativas en el área hacendaria fueron señaladas tempranamente por el ministro Araújo Viana en su informe en 1832 y fueron reiteradas continuamente por sus sucesores. ${ }^{46}$ En la década de 1840, los pocos cambios que marcaron la administración hacendaria fueron la creación del Juzgado Privado de la Hacienda en primera instancia (Ley del 29 de noviembre de 1840) y la reforma de la Secretaría de Finanzas (Decreto del 19 de abril de 1844). ${ }^{47}$

La década de 1850 marcó la consolidación del Estado Imperial, con reformas en el área de la administración hacendaria bajo la responsabilidad del ministro Joaquim José Rodrigues Torres, mediante el Decreto núm. 736, del 20 de noviembre de 1850. Este decreto estableció una distinción entre dos instancias jerárquicas de la Hacienda. El primero fue la "Suprema Administración de la Hacienda Nacional" a cargo del "Tribunal del Tesoro Nacional", que debía ser formado por el ministro de Hacienda, como presidente, y cuatro miembros nombrados por el emperador, los cuales servían como: 1) director general de las rentas públicas; 2) director general de gasto público; 3) director general de contabilidad; y 4) procurador fiscal del tesoro. Un cambio importante fue otorgar al tribunal poderes deliberativos en asuntos relacionados con cuentas, apelaciones y conflictos de jurisdicción, bien como la imposición de multas, expandiendo así los poderes del colegiado en comparación con la estructura anterior, en la cual el poder deliberativo era ejercido exclusivamente por su presidente. Se mantuvieron poderes consultivos sobre asuntos relacionados con los procedimientos para la recaudación, distribución y contabilidad de los ingresos públicos, legislación y procedimientos, contabilidad y sistema de contabilidad, presupuesto, remuneración de los

44 Sin verse afectado por las reformas que reorganizaron la administración en la década de 1840, el Tesoro experimentó cambios menores en su organigrama, como la creación de nuevas secciones de la Contabilidad General de Revisión: contabilidad y archivo, balance, toma y revisión de cuentas y deuda pública (Decisión núm. 213, del 15 de abril de 1840) y de asentamiento (Decisión núm. 281, del 11 de enero de 1840). Véase CAMARGo, Angelica Ricci, "Juntas da Real Fazenda", 2013.

45 Idem.

46 Véanse las memorias de Hacienda de los ministros VAsConcelos, Bernardo Pereira de, Relatorio, 1832, Almeida, Miguel Calmon du Pin e, Proposta e relatorio, 1838, y Branco, Manuel Alves, Proposta e relatorio, 1845. 
empleados, contratos de ingresos y gastos, administración de los bienes nacionales y organización de balances y presupuestos.

El Tesoro Nacional correspondió a la segunda instancia jerárquica de la Hacienda, constituyendo la "administración central de Hacienda". Se dividió en secciones: Secretaría de Estado de Negocios de Hacienda, Dirección General de Ingresos Públicos, Dirección General de Gastos Públicos, Dirección General de Contabilidad, Dirección General de Litigios, Tesorería General y $1^{\mathrm{a}}$ y $2^{\mathrm{a}}$ Pagaduría del Tesoro. La Secretaría de Estado de Negocios de Hacienda fue responsable del archivo y la correspondencia del ministro y el Tribunal del Tesoro. La Dirección General de Ingresos Públicos estaba a cargo de la dirección, inspección y fiscalización de la recaudación y administración de las rentas generales, la administración de los bienes nacionales y las estadísticas. El Directorio General de Despensas Públicas fue responsable de dirigir e inspeccionar el trabajo de todas las oficinas hacendarias en relación con los gastos, dirigir operaciones de crédito y movimientos de fondos, escriturar los créditos, rubricar los billetes del tesoro y firmar las políticas de la deuda pública interna. Era responsabilidad de la Dirección General de Contabilidad tomar cuentas anuales de los empleados de las provincias y la Corte, hacer la contabilidad, organizar los balances y los presupuestos generales, hacer el asentamiento del personal civil y eclesiástico. Quedaba a cargo de la Dirección General de Litigios determinar los términos de los arrendamientos, garantías y contratos, organizar al personal y cobrar la deuda activa de la Nación. La Tesorería General fue la división a través de la cual ingresaron las sumas recaudadas por los otros departamentos en la Corte y en la provincia de Río de Janeiro o cualquier otra operación practicada por estas. La $1^{a}$ Pagaduría fue responsable de pagar los sueldos de los empleados, pensiones, tenencias, montepío y medios sueldos, y la $2^{\text {a }}$ Pagaduría fue responsable de los otros pagos realizados por el Tesoro. Finalmente, la oficina del notario se encargó de depositar y clasificar los documentos del Tesoro y otras secciones. Como en la reforma anterior, también se reestructuraron los tesoros provinciales, que ahora tenían sus propios procuradores fiscales.

\section{EL PLAN DE LA ADMINISTRACIÓN REGIONAL: DE LAS JUNTAS DE HACIENDA AL TESORO PROVINCIAL}

En la punta de la administración hacendaria colonial, la recaudación de rentas e impuestos en la América portuguesa, en su período inicial, se realizó a través de los cabildos. El control de esta administración al comienzo de la constitución de las capitanías se debió a la creación de los puestos de supervisor (feitor) y almacenista para las rentas reales y para administrar las factorías. Sin embargo, con el proceso de centralización del gobierno de los territorios coloniales y la constitución de un gobierno general a partir de 1548, las proveedurías de hacienda y aduanas se crearon para mejorar el ejercicio de inspección, función para la cual tenían también la ayuda de los gobiernos de las capitanías y ayuntamientos. Sin embargo, desde el comienzo del siglo XVII hasta la segunda década 
del siglo XVIII, el control de las rentas por parte de las cámaras fue cuestionado en casos de rebeliones o rivalidades locales. A partir de 1720, las proveedurías de hacienda tomaron el control directo de los impuestos y derechos recaudados. Los contratos comenzaron a ser controlados directamente por el Consejo Ultramarino, que duró hasta la segunda mitad del siglo XVIII a partir de los cambios institucionales y las reformas hacendarias de Pombal, como ya fue explicado anteriormente. ${ }^{48}$ Las proveedurías y, en consecuencia, los proveedores, perdieron gradualmente su importancia ante las Juntas de Hacienda, creadas en ultramar desde 1765 a través de cartas reales. Después de 1774, las proveedurías persistieron solamente en capitanías donde los nuevos órganos no estaban constituidos.

Las Juntas de Hacienda, o más bien, las Juntas de Administración y Recaudación de la Real Hacienda, como su nombre lo indica, deberían centralizar las actividades de administración y recaudación de los ingresos de Real Hacienda de sus respectivas jurisdicciones territoriales en ultramar. Fueron creados en el contexto de reformas en la administración hacendaria del reino, particularmente la constitución del Erario Regio en Portugal, en 1761. En general, fueron presididos por el gobernador (o virrey), el defensor del pueblo o el juez externo que ocupó los cargos de juez ejecutor y procurador de la Hacienda; los demás cargos como tesorero general, secretario y contador fueron elegidos en la misma junta y dependían de las características asumidas por el organismo de acuerdo con el lugar en el que se estableció, así como sus atribuciones podrían variar según las circunstancias y las extensiones territoriales a ser administrado. Las Juntas debían administrar los ingresos reales y promover su recaudación a través de la subasta e inspección de contratos, así como la subasta de los oficios de magistratura. Dichos ingresos debían ser utilizados para pagos de los sueldos eclesiásticos, civiles y militares. La remuneración de los servicios de tropas, que, por cierto, era una de las principales actividades y estaba indisolublemente vinculada a la creación del Erario Regio, es decir, la administración económica del territorio, pensada y gestionada de manera más integrada, entendiendo las fronteras como parte fundamental de la política estatal moderna. Estamos hablando aquí sobre las atribuciones jurídicas de la administración hacendaria que concentraron los poderes, en un organismo ultramarino, de jurisdicción voluntaria y jurisdicción contenciosa. Finalmente, en ultramar, las Juntas tendrían que comprender las atribuciones competentes al Erario Regio y al Consejo de Hacienda, desmembrados en el reino después de las reformas del marqués de Pombal. Sin embargo, tales características sufrieron algunas reformulaciones con el traslado de la Corte a Río de Janeiro y la recreación, en América, de los órganos de la administración superior.

El alvará del 28 de junio de 1808, que estableció la creación del Erario Regio y el Consejo de Hacienda en Brasil, junto con la extinción de la Junta de Hacienda en Río de Janeiro, nos aclara sobre las nuevas jurisdicciones. Los territorios de las Contadurías fueran divididos y nuevamente se definieron en tres grandes áreas fiscales, entendiéndose solo los llamados dominios ultramarinos, ya

48 CAmargo, Angelica Ricci, "Juntas da Real Fazenda”, 2013, y AidAr, Bruno, “Governar a Real Fazenda”, 2013. 
que la institución portuguesa y la contabilidad del reino no dejaron de existir. Las prerrogativas del nuevo Consejo de Hacienda serían las mismas que las de Portugal, con la misma estructura y presidencia, es decir, el mismo inspector general y presidente del Erario Regio con jurisdicción sobre las zonas e islas coloniales. Con la excepción de la Junta de Hacienda de Río de Janeiro, todos los demás se mantendrían, pero ya no estarían bajo la jurisdicción del Consejo de Ultramar, como se definió expresamente en la misma carta. Otra característica importante relacionada con las jurisdicciones voluntarias y contenciosas fue la transferencia de ellas en el caso de la entonces extinta Junta de Hacienda de Río de Janeiro para el Consejo de Hacienda. En las otras Juntas, este aspecto no fue cambiado por el alvará, pero, en la práctica, las cartas reales después de esa fecha especificaban mejor estas funciones. En ellos, la jurisdicción contenciosa estaba específicamente bajo la responsabilidad del defensor del pueblo general (miembro de la Junta) y la voluntaria, bajo la responsabilidad del "cuerpo de la Junta" ${ }^{49}$ En este período posterior a la transferencia de la Corte, se crearon las Juntas de Hacienda de Paraíba, Espírito Santo, Mato Grosso, Piauí, Santa Catarina, Alagoas, Rio Grande do Norte y, finalmente, Sergipe, cubriendo, desde allí, todo el territorio del Reino de Brasil. ${ }^{50}$ En el caso de Sergipe, el tema era un poco más complejo ya que la fecha de la carta (a fines de la década de 1820) chocaba con los cambios políticos e institucionales iniciados en el año siguiente como parte de los efectos de la revolución de Oporto y de la convocatoria de las Cortes. Entre estos cambios, el más significativo para las juntas fue el establecimiento de gobiernos provinciales provisionales. Con eso, la Junta de Hacienda de Sergipe solo se creó en 1826, después de la independencia. La sesión del 3 de septiembre de 1828 de la Cámara de Diputados, en su comisión de Hacienda, se dio cuenta de que, en 1823, durante el gobierno provisional de esa provincia, se había constituido una Junta de Hacienda, pero sin ninguna autorización de una carta real o de organismos administrativos superiores. No fue sino hasta 1826 que esta situación se regularizó. ${ }^{51}$ Por lo tanto, esta habría sido la última y más breve Junta de Hacienda en Brasil.

En vista de las tensiones entre Lisboa y Río de Janeiro, además de las que surgen de la dinámica de las provincias, este período entre los años 1821 y 1823 fue particularmente complicado y decisivo, tanto para la supervivencia de las Juntas de Hacienda, como por demostrar la fragilidad de una estructura fiscal fragmentada basada en poderes y fuerzas regionales. Entre la revolución de Oporto, la Independencia de Brasil y el Constituyente de 1823, las instituciones hacendarias estaban en la mira de importantes discusiones. Ambas estaban en la base de los debates sobre soberanía $\mathrm{y}$, por supuesto, de proyectos que darían lugar a una mayor centralidad administrativa dentro de la América portuguesa. En medio de los procesos autónomos de constitución de las Juntas Provisionales de Gobierno, las cortes en Lisboa decidieron emitir un decreto por su uniformidad y

49 Véase, por ejemplo, la carta regia del 15 de julio de 1818 sobre la capitanía de Alagoas.

50 Camargo, Angelica Ricci, "Juntas da Real Fazenda", 2013.

51 Sesión de la Cámara de Diputados del 3 de septiembre de 1828, en Annaes do Parlamento, t. II, p. 183. 
control..$^{52}$ Por lo tanto, determinaron el número de representantes que deberían ser elegidos en las provincias, sus deberes, remuneración, formas de elección, de mismo modo, determinaron que se les otorgaría "toda autoridad y jurisdicción en las áreas civil, económica, administrativa y política de acuerdo con las leyes existentes", pero hubo reservas con respecto al gobierno militar y el control de la Junta de Hacienda. ${ }^{53}$ En primer lugar, porque los puestos de gobernador de armas serían creados, ocupados por oficiales militares, independientes de las Juntas y subordinados al gobierno del Reino. Segundo, porque la administración hacendaria había cambiado su composición anterior y también estaba subordinada al gobierno del Reino. En este caso, las Juntas de Hacienda, anteriormente presididas por gobernadores/capitanes generales, fueron presididas por su miembro más antiguo, con la excepción de los tesoreros y empleados. Aunque no estaba prohibido, como se estipuló en 1822, la coincidencia entre los presidentes de las juntas provisionales de gobierno y las Juntas de Hacienda, el Decreto del 29 de septiembre de 1821 lo hizo mucho más difícil. Esto podría garantizar una cierta independencia de la Hacienda en relación con el gobierno regional más autónomo.

Hasta ese período, podríamos destacar solo tres movimientos concretos más en torno a alguna forma de centralidad fiscal en territorio americano, independientemente de los organismos gubernamentales superiores antes mencionados, como el Erario Regio y el Consejo de Hacienda, todavía representaban el control colonial más amplio: el primero fue el proyecto de las "sobras" de los diversos departamentos hacendarios de las capitanías propuesto en 1812 por el escribano del Erario Regio, Manuel Jacinto Nogueira da Gama (futuro ministro de Hacienda en el primer reinado). El segundo fue la creación del cargo de ministro y secretario de Estado de Negocios de Hacienda el 6 de marzo de 1821 por las Cortes en Lisboa, lo que, en ese contexto, fortaleció la posición de D. Pedro en Brasil. ${ }^{54} \mathrm{Y}$, finalmente, la constitución de una Comisión de Hacienda instituida por D. Pedro a principios de 1822 que produciría un primer informe sobre las condiciones fiscales reales de las diferentes provincias:

Si las otras provincias de este Reino continuaron enviando, como antes, al Tesoro, los remanentes de sus rentas [...] pero actualmente no tenemos estas sobras, ni sabemos cuándo podremos contar con ellos, y nuestros cálculos no estarán bien fundados si esperamos obtenerlos antes de que veamos radicadas la unión de las provincias más importantes, y si sus respectivos gobiernos se establecen sobre bases más seguras; ni es la prudencia de estos [gobiernos] en la vigilancia y la fermentación en la que se encuentra todo, enviar hacia fuera las sumas más pequeñas. En

52 Decreto provisional que describe el sistema de gobierno y administración pública en las provincias de Brasil, núm. 322, del 29 de septiembre de 1821 en Collecção dos decretos, 1822, pp. 225-226. Antes de este decreto, las Juntas ya creadas tenían solo el respaldo de la casa legislativa portuguesa a través del decreto del 18 de abril (Decreto núm. 45, publicado el 5 de mayo de 1821, las cortes determinaron las medidas con respecto a "las elecciones en ultramar y otras medidas sobre los pueblos que abrazan la Regeneración política, o que se oponen", en Ibidem, p. 49.

53 Decreto provisional que describe el sistema de gobierno y administración pública en las Provincias de Brasil, núm. 322, del 29 de septiembre de 1821, en Collecção dos decretos, 1822, pp. 225-226.

54

Chaves, Cláudia, "Os poderes regionais", 2018. 
vista de esto, la comisión caería en la misma condición si, después de mostrar la urgencia del pago de las deudas con las que trata, propuso a su Alteza Real, ordenarle que reserve para tiempos inciertos del restablecimiento de la unión, y la tranquilidad general de todas las provincias; u olvidando el estado actual de la renta ordinaria, quisiera por ella hacer el pago de un gasto grande y extraordinario. ${ }^{55}$

Las fricciones y adherencias, o no, a los proyectos de D. Pedro I también reflejaron la ausencia de una unidad nacional previa, que todavía estaba profundamente vinculada a los arreglos políticos y los grupos en disputa dentro de las provincias recién formadas. El mencionado caso de Sergipe se volvió extremo, pero no fue diferente de las luchas entre las diversas cámaras y los gobiernos regionales, así como entre las Juntas de Hacienda y las Juntas de Gobierno. ${ }^{56}$ En este sentido, tales conflictos sirvieron como combustible para los debates parlamentarios al comienzo del trabajo en la Cámara de Diputados después de 1826 y, en consecuencia, para la elaboración de una remodelación de la estructura en la administración hacendaria en el centro y en las provincias. Las críticas a las Juntas de Hacienda fueron recurrentes y entre ellas se encontraba la idea de ineficiencia, la ausencia constante de "sobras", la disparidad en la recaudación y administración en cada uno de ellos, pero también es verdad que las juntas más centrales y antiguas, como de Minas Gerais, São Paulo y Bahía, se encontraban entre las más regulares en la organización e información.

El informe del ministro y secretario de Hacienda Miguel Calmon Du Pin e Almeida, leído en la Cámara de Diputados en la sesión del 11 de junio de 1828, decía que:

Es incuestionable lo perjudicial que debe ser a la Hacienda la acción lenta de estos organismos colectivos o tribunales que administran las rentas en las provincias. Secciones periódicas y fórmulas innecesarias retrasan los negocios y desperdician el tiempo. [...] Además de ser lentas, las Juntas de Hacienda son inútiles y extremadamente gravosas para el estado en las provincias de Mato Grosso, Goiás, Piauí, Río Grande do Norte, Espíritu Santo y Santa Catarina. Los ingresos de estas provincias son casi absorbidos por los gastos de las Juntas. El gobierno, como por ensayo, ordenó el establecimiento de una administración hacendaria en la provincia de Sergipe, sobre las ruinas de cierta Junta que se había organizado allí durante la revolución. [...] si la Asamblea General, al no poder reorganizar en esta sesión todas las reparticiones de Hacienda, se basa en la conveniencia de extinguir desde ya las que considere innecesarias. La falta de uniformidad en la contabilidad es tan notable que el método de partida doble solo se conoce en las Contadurías Generales del tesoro. Las Juntas también siguen la contabilidad simple, lo que resulta además de serias irregularidades en la dificultad de extraer los balances anuales [...]. El examen moral de las cuentas ya sea proporcionado por las Juntas, o por los administradores y recaudadores del Tesoro, es, y debe ser, la más esencial de las atribuciones del tesoro público. ${ }^{57}$

\footnotetext{
55 Viana, Vitor, Histórico da formação, 1922, p. 196.

56 Chaves, Cláudia, "Os poderes regionais”, 2018.

57 Sesión de la Cámara de Diputados del 11 de junio de 1828, en Annaes do Parlamento, t. II, p. 96.
} 
Tales críticas, sistemáticamente repetidas en los últimos años del Primer Reinado, sin duda allanaron el camino para las reformas estructurales de la Hacienda que ya hemos mencionado con la creación del Tesoro Público Nacional y los Tesoros Provinciales. Estas tesorerías, así como las juntas, fueron responsables de la administración, recaudación, distribución, contabilidad e inspección de los ingresos públicos y de todas las unidades fiscales locales. Además, de manera similar a las Juntas, fueron dirigidas por los presidentes de sus respectivas provincias. Absorbieron los cambios propuestos a fines de la década de 1820, como las funciones de las Mesas de Inspección y la recaudación de la décima urbana. ${ }^{58}$ Además, desde 1827, las Juntas se encargaron de designar colectores para recoger los impuestos.

Como resultado de este proceso, fueron creados por la Decisión núm. 63, el 8 de febrero de 1832, las colecturías generales de las provincias. Ellas eran compuestas por un colector y un escribano y tenían como distrito un conjunto de colecturías especiales de acuerdo con las distancias y capacidades para la gerencia de un funcionario. Subordinados a las Tesorerías provinciales, tenían como objetivo controlar y supervisar el trabajo de los colectores, incluida la inspección de delitos por los cuales podían exigir a los tribunales territoriales que confiscaran los bienes de los colectores que no hiciesen correctamente los pagos de los ingresos recaudados. Ese mismo año, una serie de regulaciones, como la regulación de la recaudación de polvo de oro (Decisión núm. 72) y la regulación de la recaudación de diezmos (Decisión núm. 125) complementaron el conjunto de deberes de la administración hacendaria en las provincias. Aunque este proceso había contribuido a una estandarización en las divisiones hacendarias en las provincias, ellas todavía recibían críticas de las élites regionales por el control excesivo del gobierno. Estas quejas de alguna manera fueran reducidas a partir del Acto Adicional de 1834 que otorgó mayor libertad para que las provincias decidieran sobre los impuestos por medio de sus asambleas provinciales.

En 1850, como ya nos hemos referido al Decreto núm. 736, una serie de nuevas reformas en la Hacienda, en pleno Segundo Reinado, y en parte como una reformulación de las propuestas más descentralizadoras del período de la Regencia, cambió nuevamente la organización provincial. El tesoro provincial de Río de Janeiro se extinguió con sus deberes reorganizados entre los Directorios Generales de Rentas Públicas, Tesorería General y Pagadurías del Tesoro. ${ }^{59}$ Con base en que en esta época no había uniformidad entre los diversos tesoros provinciales, se hizo un intento por lograr un equilibrio en términos organizacionales y equiparar sus estructuras. Con la regulación de la tesorería de la Hacienda, por el Decreto núm. 870, del 22 de noviembre de $1851,{ }^{60}$ se promovió la estandarización y definición más completa, hasta entonces, de las competencias provinciales en materia de administración hacendaria: atribuciones, secciones de la junta, secciones de litigios, secretarías, contadurías, tesorerías, oficinas de pago y notarios.

58 Barcelos, Fábio Campos, A Secretaria de Estado, 2014, p. 36.

59 GABLER, Louise, "Tesourarias das províncias", 2016.

60 Esta regulación también sufrirá algunos cambios con el Decreto núm. 2343 del 29 de enero de 1859. 
Está claro que todas las excepciones, producidas por las particularidades económicas de las provincias, fueron debidamente referenciadas.

Más de una década después, en el contexto de posguerra de Paraguay, se llevó a cabo una nueva reforma hacendaria a través del decreto núm. 5254, del 5 de abril de 1873. A través de ella, se extinguieron cargos y algunas direcciones de las tesorerías provinciales. Según Barcelos, este habría sido uno de los últimos cambios importantes del período imperial hasta el comienzo del período republicano, que reorganizó toda la administración hacendaria por el tamiz de un sistema federal que, en consecuencia, confirió nuevos poderes administrativos a los estados. ${ }^{61}$ Sin embargo, debe recordarse que las tesorerías provinciales y colecturías fueron definitivamente extinguidas por el artículo núm. 12 de la Ley núm. 23 de 30 de octubre de 1891.

\section{LAS BASES DE LA RECAUDACIÓN: REMATANTES DE IMPUESTOS Y ADMINISTRACIÓN DIRECTA}

En el período colonial, la mayor parte de la recaudación de impuestos en la América portuguesa estaba bajo la responsabilidad de los rematantes de impuestos, a excepción de los importantes ingresos de los quintos cobrados sobre el oro. ${ }^{62}$ Debe recordarse que los impuestos eran parte del amplio sistema de ofertas que incluía bienes de consumo almacenados por la Corona (aguardiente, cartas de juego, derivados de la pesca de ballenas, ganado, jabón, sal y tabaco) y suministros para las tropas militares (harina, uniformes, pólvora etc.). El concepto de contratador (rematante) presente en el diccionario Bluteau en las primeras décadas del siglo XVIII denota este carácter general, designándolo como un "hombre de negocios de la plaza, que contrata en varios géneros". ${ }^{63}$

Una medida muy antigua utilizada desde el Imperio Romano, la formación de estados modernos e imperios coloniales reanudaría este mecanismo relativamente simple con gran ímpetu, expandiendo esta práctica en Europa, América y parte de África. Los imperios ruso y otomano también recurrieron al sistema de arrendamiento, lo que hace imposible considerar este sistema como un fenómeno exclusivamente europeo. Para el Estado, en teoría, representaba una oportunidad para obtener ingresos ciertos y continuos, para reducir los costos de la administración directa de impuestos y para transferir a terceros las dificultades de recaudar

61 Barcelos, Fábio Campos, A Secretaria de Estado, 2014, pp. 55-56.

62 La literatura sobre los rematantes de impuestos del imperio colonial portugués en siglo XVIII y en las primeras décadas del siglo XIX es bastante larga. Muchas de estas investigaciones fueron desarrolladas a partir de los trabajos clásicos de Myriam Ellis, Maria Thereza Schörer Petrone y, más recientemente, Jorge Pedreira. Para estudios sobre los rematantes en las diferentes regiones del imperio véanse AIDAR, Bruno, "A vereda dos tratos", 2013, ARAúso, Luís Antônio Silva, "Em nome do rei", 2008, Carrara, "A administração dos contratos", 2011, Ellis, Myriam, "Comerciantes e contratadores", 1982, Menz, Maximiliano, "Domingos Dias", 2017, Miranda, Marcia Eckert, A estalagem e o império, 2009, Neves Neto, Raimundo Moreira, Em aumento de minha fazenda, 2019, Pedreira, Jorge, "Os homens de negócio", 1995, Pesavento, Fábio, y Guimarães, Carlos Gabriel "Contratos e contratadores", 2013, Petrone, Maria Thereza Schorer, O Barão

63 Bluteau, Raphael, Vocabulario portuguez, 1712-1728, vol. 2, p. 511. de Iguape, 1976, y SANTOS, Iara Dias dos, "Os contratos dos dízimos", 2018. 
sobre poblaciones heterogéneas y a menudo rebeldes. Un aspecto poco notado fue la capacidad de expandir rápidamente el alcance de la red fiscal sin la necesidad de estructurar una red de estaciones hacendarias costeadas por el Estado. Esta capilaridad se profundizó por el uso de la venta de partes (ramos) de contratos a terceros, como ocurría a menudo con los diezmos.

A su vez, los rematantes obtuvieron enormes ganancias de la diferencia entre el monto recaudado y el precio pagado en la subasta por los contratos. Las ganancias podrían incrementarse con la combinación de prácticas comerciales (reventa de productos y subvaluación de las mercancías in natura) y prácticas financieras asociadas a la recaudación (préstamos a interés a los contribuyentes y asociación de la obtención de contratos en cambio de préstamos al Estado). También era un negocio arriesgado. El rematante podría tener recursos insuficientes para pagar el monto prometido, lo que finalmente podría conducir a la quiebra y ejecución fiscal, bien como los montos recaudados podrían ser menores que la ganancia esperada inicialmente debido a cosechas escasas, magros rebaños, guerras o incluso a la revuelta de los contribuyentes.

La estructura vertical de la recaudación tenía un grado variable de concentración, dando lugar a una gran variedad institucional. En el límite, los contratos más importantes se unificaron en una gran subasta, como fue el caso de Ferme Générale, creada en Francia en 1598. También fue posible articular la subasta a agentes distintos de los rematantes, como en los contratos alternados entre rematantes, cabildos y consulados en Nueva España en la primera mitad del siglo XVIII. En este punto, los dominios portugueses siguieron caminos más fluidos con respecto a la organización de su cuerpo mercantil. En el caso portugués, se mantuvo una estructura menos concentrada que la francesa, aprovechando la competencia de los rematantes de impuestos del reino entre sí y entre estos y los rematantes de los dominios ultramarinos, en un movimiento pendular a lo largo del siglo XVIII entre Lisboa y las capitanías generales en el América portuguesa.

La dispersión favoreció un cierto grado de competencia entre los mercaderes por los contratos, fomentando fracciones mercantiles en diferentes planes del imperio. El juego de la corona portuguesa en la búsqueda de grandes pagos era entre subastar en Lisboa o en los dominios de ultramar, y en el último entre la capital del virreinato y las capitanías generales. Las posibles combinaciones se incrementaron aún más dividiendo y separando los contratos. Así, de un momento a otro, los hombres de negocios en la América Portuguesa asistirán a la apertura o al cierre de las puertas de acceso a los contratos de impuestos pequeños y grandes de sus respectivas capitanías. La complejidad era ampliada por el empleo del sistema de arrendamiento a nivel local (pueblos y ciudades), regional (capitanías generales) e imperial.

Obviamente, el asunto tenía serias implicaciones sociales y políticas, y no se limitaba a la grandeza de los ingresos estatales, como Montesquieu señaló a mediados del siglo XVIII. En diferentes momentos, la duda entre recaudación por contrato o cobranza por administración directa resonó en las principales mentes ilustradas de Francia, España, Portugal y en los reinos italianos. Entre los ingleses, 
la cuestión ya se había resuelto a favor del estado a fines del siglo XVII. Montesquieu, que conocía muy bien la historia romana, prefería la administración directa para evitar los vicios de los contratos. No era solo una cuestión económica el problema del empobrecimiento del príncipe y sus súbditos por parte de los rematantes, sino también profundamente política, la autonomía del príncipe frente a una clase basada en la riqueza. Esta inversión, continuó el barón, impregnó la historia de los perjuicios de los rematantes en las monarquías y las repúblicas, como lo señaló el ejemplo romano. El poder de los rematantes avanzó tanto sobre el pueblo como sobre el soberano mismo, que se sometió al poder financiero de los primeros, obligando al príncipe a hacer leyes para su beneficio, incluso si no eran legisladores. ${ }^{64}$

Después del gran período de fortalecimiento del Consejo Ultramarino y de los negociadores del reino, principalmente en la subasta de los contratos de la América portuguesa entre las décadas de 1720 y 1750, la arquitectura fiscal de la época del marqués de Pombal aún insistirá en la preferencia por los contratantes, instituyendo nuevas formas de control en el centro (el Erario Regio) y en las partes del imperio (las Juntas de Hacienda), así como redistribuir, en una división de la organización imperial, los contratos de tributos entre las élites del reino y los negociantes de ultramar. Cabe señalar que las reformas hacendarias encabezadas por el marqués de Pombal nunca tuvieron como objetivo la extinción de los rematantes, sino más bien racionalizar el proceso de adjudicación de contratos, especialmente teniendo en cuenta las entradas y salidas de dinero de las numerosas venas del cuerpo monárquico.

Un pequeño ejemplo muestra esta primacía de la recaudación privada. En 1767, el gobernador de Minas Gerais alertó al conde de Oeiras, luego marqués de Pombal, y entonces presidente del Erario, sobre las pérdidas en el contrato de entrada y solicitó la administración directa, evitando tanto la falta de pago por parte de los rematantes como la violencia en la recaudación, que perjudica el comercio. El conde de Oeiras criticó fuertemente al gobernador y destiló fuertes sospechas sobre la administración directa. En su opinión, los empleados de la Real Hacienda no tenían las habilidades necesarias, ni el celo, ni la probidad para cobrar las rentas de la mejor manera posible: "no es fácil encontrar a esos oficiales tan inteligentes tan honrados; y tan celosos, que tengan la capacidad necesaria para la buena recaudación, que no prevariquen en el abuso de los capitales que manejan, y que se interesen en promover esos medios de los cuales puede derivarse el aumento de estos derechos". ${ }^{65}$ Además, los funcionarios de la Real Hacienda representaron costos para la recaudación de impuestos y además eran difíciles de investigar en caso de irregularidades en fraudes y omisiones. Sería mejor confiar en el interés propio de los rematantes, que era la motivación conducente al aumento de la Real Hacienda: "La razón del interés propio equivale en los rematantes a todos los mas predicados que se hacen indispensables en los oficiales reales,

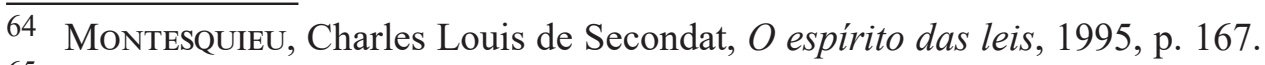

65 Carta del conde de Oeiras al conde de Valadares, Lisboa, 8 de febrero de 1768, en Archivo Histórico del Tribunal de Cuentas (en adelante AHTC), Erario Regio, códice 4072, f. 38. 
para que haya una buena administración". ${ }^{66}$ La insolvencia y la violencia extractiva de los rematantes, el estadista creía, podría resolverse con la vigilancia de los ministros del rey, una referencia expresa a las nuevas Juntas de Hacienda creadas en ese momento y de las que hablaremos en el último tópico.

Unos años más tarde, en una serie de instrucciones sobre la administración y recaudación de la Real Hacienda recibidas por la Junta de Hacienda de la capitanía de São Paulo en 1775, uno de pilares del ideal pombalino de la administración hacendaria era la atracción de buenos rematantes, al arrendar los tributos "a las personas más ricas y laboriosas", a los "mejores negociantes" ${ }^{67}$ La exaltación de los rematantes en las instrucciones firmadas por el marqués, reiterando las concepciones fiscales de los gobiernos anteriores, se manifestaba por las críticas a la administración directa de los tributos por parte de la Real Hacienda. En opinión de Pombal, un administrador nunca haría tanto esfuerzo para recaudar rentas difíciles y sujetas a pérdidas como un rematante "que multiplica la vigilancia y hace los gastos a su discreción, trabajando por su propio bien, impulsado por el deseo de ganancias y el miedo a las pérdidas". Solo en casos muy específicos relacionados con incidentes casuales, como desastres naturales, los ingresos se debían administrar directamente. Incluso en este caso, la medida debería permanecer en vigencia por un corto tiempo, aconsejándose un año, hasta que las rentas fueran subastadas en mejores condiciones.

Se puede ver en las instrucciones que los buenos negociantes no eran aquellos que no debían a la Real Hacienda, sino aquellos que, debido a razones circunstanciales, como demoras en la circulación de bienes y falta de pagos de contribuyentes, pospusieron el pago de las cuotas de los contratos a la Junta de Hacienda. En este caso, la junta no debería ahuyentar a los mejores negociadores con cobranzas imprudentes, sino que debía "ocultar un retraso prudente [en el cobro de estas deudas temporales]". Lo contrario de estos buenos negociantes fueron aquellos que, "impulsados por la ambición", celebraron contratos sin tener suficiente capital. Poco después, pedirían el perdón de sus deudas y, cuando fueran ejecutados por sus deudas, terminarían asustando a los otros negociantes. Además de no pagar sus deudas, los rematantes considerados ambiciosos administrarían mal el contrato y contribuirían al descrédito del tributo. Sin embargo, la brecha entre negociadores buenos y malos, ricos y ambiciosos, cautelosos e imprudentes, era tenue y potencialmente sujeta al juicio de los gobernadores como presidentes de las Juntas de Hacienda.

A partir de la década de 1780, la percepción positiva de los rematantes tanto en los dominios como en el reino disminuye, especialmente debido a los vínculos entre el poder de los rematantes y las insurrecciones que buscaban derribar los tronos. En este sentido, la insurrección en Minas Gerais (la Inconfidência Mineira) y la revolución francesa, alcanzando los diferentes planes del imperio portugués

66 Ibidem, f. 38.

67 Instrucciones regias al gobernador de la capitanía de São Paulo respecto a la administración y recaudación de la Real Hacienda, Palacio de Nuestra Señora de la Ayuda, 7 de enero de 1775, en AHTC, Erario Regio, códice 4061, fs. 120-126. 
interna y externamente, contribuyeron decisivamente al avance de la fuerte crítica de los rematantes dentro de la alta burocracia estatal. La práctica de la recaudación por contratos ya no convergía para la buena administración de la Real Hacienda y para el apoyo de la monarquía. Se ha convertido en un elemento disruptivo, centrífugo en su dinámica, alejado de las intenciones de control, tal vez ilusorias, intentadas por las reformas hacendarias de Pombal. La cuestión de los atrasos de los pagos de los rematantes al Erario también fue un grave problema económico. En 1789, solo las deudas acumuladas de los contratos de impuestos de las entradas y diezmos de la capitanía de Minas Gerais representaban el $36 \%$ de los ingresos de todo el Estado portugués en ese año.

Obviamente, esta evaluación del fracaso se hizo a posteriori. En un oficio de la Contaduría General de Río de Janeiro y África Oriental en 1794, se defendía el retorno de las subastas a Lisboa por la desilusión con la experiencia de las Juntas de Hacienda, que habían sido creadas justamente para poner fin a la colusión en las subastas realizadas por el Consejo Ultramarino, especialmente la práctica de usar testaferros, entre 1723 y 1761. También se dijo que las Juntas de Hacienda, ya destituidas de su vigor inicial, habían sucumbido a los intereses privados, dejando de lado aquellos de la Real Hacienda. La mayor ventaja para el Tesoro era otorgar contratos a los negociantes "conocid[os], y de mayor crédito y abono". También se hizo hincapié en que estos negociantes eran distintos de los "Torres, Veigas, Campos, Bezerra", que habían dejado innumerables deudas contractuales en las subastas hechas en el Consejo Ultramarino. ${ }^{68}$

A pesar de sus diferentes orientaciones, dos grandes secretarios de Estado de Marina y Dominios Ultramarinos, Martinho de Melo e Castro y D. Rodrigo de Souza Coutinho, convergieron en la feroz crítica a las ganancias consideradas abusivas obtenidas por los rematantes. En particular, concordaban respecto a las condiciones privilegiadas para los rematantes en la extensión del contrato de tabaco a cambio de préstamos otorgados a la corona portuguesa en 1794 fueran consideradas demasiadamente excesivas, la última gota en los excesos de los tabaqueros. Para Melo e Castro, conocido mercantilista, el contrato fue solo un velo para extorsionar al Erario Regio, sin embargo, el ministro no llegó a pregonar la transferencia de rentas a la administración directa. ${ }^{69}$ En este sentido, Souza Coutinho formularia una propuesta de reforma hacendaria desde una perspectiva más amplia basada tanto en la lectura de críticos del sistema de recaudación, como Montesquieu y Smith, como en la observación práctica de las diferentes formas de recaudación en Francia, Inglaterra y el norte de Italia. Francia era el modelo a evitar, ya que el estado fue absorbido por las ganancias de los financieros y la revolución había sido detonada en gran parte debido a la violencia fiscal de los rematantes. En el otro extremo, Inglaterra fue un buen ejemplo, con la mayor parte de su recaudación hecha por administración directa y con un sistema de

68 Carta de la Contaduría General de Río de Janeiro y África Oriental al presidente del Erario Regio, el vizconde de Vila Nova da Cerveira, Lisboa, 22 de diciembre de 1794, en AHTC, códice 4044, fs. 142-155.

69 Melo e Castro, Martinho de, "Informe sobre la subasta de diferentes contratos, presentada al Príncipe Regente, D. João", s. 1., 1794, en Archivo Nacional (en adelante ANRJ), códice 807, vol. 2, fs. 118-125. 
crédito que permitió el financiamiento de la deuda pública. Recordando el comentario de Smith, con el cambio en lo sistema de recaudación, las ganancias excesivas de los rematantes serían absorbidas por el propio Estado. ${ }^{70}$

Acompañando las críticas hechas en la década de 1790 por la alta burocracia estatal, hubo avances en la administración directa de impuestos en muchas partes del imperio portugués. ${ }^{71}$ Angola fue el ejemplo más notable y más antiguo, con el 91\% de los ingresos administrados por la Real Hacienda a fines del siglo XVIII, el $82 \%$ de los cuales estaba representado únicamente por los valiosos derechos de los esclavos y el marfil. Solo el estanco de la sal y el contrato de los diezmos permanecieran arrendados a particulares, pero parte de este último también se administró. Al mismo tiempo, Pernambuco, Bahía y Maranhão tenían más de la mitad de sus ingresos bajo la supervisión directa de la Corona, con valores respectivos del $64 \%, 57 \%$ y $56 \%$ de los ingresos recaudados en administración directa. En Pará, los progresos habían sido menores, con solo el 31\% de los ingresos bajo administración directa. En Río de Janeiro, el diezmo de la aduana se transfirió a la administración directa a partir de 1772. En Minas Gerais, la transferencia de contratos para entradas y diezmos se transfirió a la administración directa entre 1787 y 1789.

En 1801, la abolición del estanco de la sal y el fin del monopolio de la pesca de ballenas se consideraron medidas de rompimiento en la relación entre la Corona y los rematantes, aunque la incapacidad para reformar la recaudación de diezmos fue una derrota que evidenció la continua dependencia financiera del Estado con respecto a los rematantes. La invasión francesa generó un nuevo debate sobre la dirección de la administración hacendaria. Condujo a la transferencia de la familia real y toda la corte portuguesa de Lisboa a la ciudad de Río de Janeiro. Como resultado, los órganos de la administración central se recrearon en América, incluidos el Erario Regio y el Consejo de Hacienda. Por un lado, esta replicación por parte de los órganos hacendarios profundizó el sistema de contratación de las élites mercantiles en las capitanías generales. Por otro lado, la invasión produjo enormes pérdidas económicas que afectaron a los rematantes y su capacidad de recaudación. Una breve mirada al balance de ingresos y gastos en el reino en 1810 muestra que la gran mayoría de los ingresos ya estaban bajo administración directa, con la excepción de los estancamientos de tabaco, jabón y palo de Brasil. ${ }^{72}$

Aparentemente, la revolución liberal de Oporto no tuvo consecuencias en la redefinición del asunto, pero debe hacerse a excepción del Decreto del 16 de abril de 1821, emitido por el gobierno de Río de Janeiro, que transformó los diezmos en impuestos de exportación. Este cambio también condujo a la transferencia de

\footnotetext{
70 AIDAR, Bruno, "Uma substituição luminosa", 2011.

71 Relación de los ingresos subastados y administrados de la Real Hacienda en las capitanías, Contaduría General de África Occidental y Bahía, [Lisboa], 28 de diciembre de 1799, en AHTC, Erario Regio, Cartórios Avulsos, caja 116, documento 12.

72 Cuadro general de ingresos y egresos del Erario Regio del primero semestre de 1810, en ANRJ, Erario Regio, caja 784 , paquete 1 .
} 
la administración por contratos a la administración directa en registros y aduanas de puertos secos. El preámbulo del decreto es notable al señalar los aspectos negativos involucrados en su recopilación de una forma $u$ otra. La administración directa pecaba por su alto costo y por la baja confianza en los oficiales: "siendo el primero extremadamente dispendioso para los sueldos, que absorben a los muchos administradores, necesarios en un territorio tan vasto, y raramente rentables por la dificultad de encontrar en todos ellos la probidad indispensable". ${ }^{73}$ El sistema de subastas, a su vez, era "absolutamente intolerable por las ganancias excesivas que se acumulan en sí, y sus socios los rematantes, lo cual es muy difícil de remediar". ${ }^{74}$ Los rematantes acosaban al pueblo tanto económicamente, extorsionándolo con transacciones fraudulentas, como jurídicamente, debido a los altos costos de defensa de los contribuyentes para resolver disputas en el fuero de la Real Hacienda.

La independencia de Brasil volvería a revivir la cuestión planteada por el reformismo ilustrado sobre la elección entre administración directa y el arrendamiento. Además del gasto público en Río de Janeiro, los préstamos extranjeros en Londres presionaron las reformas. Martim Francisco Ribeiro de Andrada, primer ministro de Hacienda abogó, alrededor de 1825, por la administración directa, la mejor forma "según los buenos principios de la economía política" y que trataría de aplicar, aunque de forma circunscrita a Río de Janeiro, con la creación de la Administración de Rentas Públicas. Para Martim Francisco, las subastas eran sinónimo de "monopolio, opresión de la gente y daños a los bienes públicos, un método que tal vez solo es posible en gobiernos despóticos". ${ }^{75}$ Sin tales reformas, no sería posible pagar préstamos en el extranjero, dijo el exministro. En la misma línea de denuncias de los abusos de los rematantes, Bernardo Pereira de Vasconcelos, aún dentro del alcance del gobierno provincial de Minas Gerais, señalaba que debía evitarse cualquier recaudación de impuestos onerosa y opresiva al pueblo, advirtiendo que "no se deben arrendar las rentas, siendo los rematantes no pocas veces opresores". ${ }^{76}$ En 1831, el vínculo entre el sistema de contratos y la forma de gobierno despótico y absolutista también estaría presente en el discurso del ministro de hacienda, José Inácio Borges, que asoció, por oposición, la administración directa a los modelos liberales de gobierno. Por lo demás, solo reiteró los temas de opresión de los contribuyentes y el enriquecimiento exacerbado de los rematantes. ${ }^{77}$

A pesar de la creación de la Tesoro Nacional y las Tesorerías Provinciales en 1831, que marcó la ruptura con la organización anterior fundada sobre el Erario Regio y las Juntas de Hacienda, las décadas posteriores a la independencia demostraron la enorme dificultad para deshacerse de las subastas de los contratos. Un comentario de un manual de derecho financiero a mediados del siglo XIX

$\overline{73 \text { Decreto del } 16}$ de abril de 1821.

74 Idem.

75 Cartas andradinas, 1890, p. 64.

76 Vasconcelos, Bernardo Pereira de, "Parecer sobre o systema", 1903, p. 643.

77 Borges, José Ignacio, Relatorio do ministro, 1831, p. 5. 
sintetiza la distancia entre el ideal y la práctica de la administración hacendaria, derrumbándose los intentos de extinción de los arrendamientos y permitiéndose su supervivencia: "En principio rechazamos el arrendamiento de los contratos de rentas públicas, no obstante nos vemos obligados a aceptar que, dadas nuestras circunstancias muy especiales, a veces son necesarios en ciertos lugares". ${ }^{78} \mathrm{Al}$ mismo tiempo, el ministro de Hacienda se manifestaba un poco avergonzado por el retorno selectivo (total o parcial) de los arrendamientos para mejorar la recaudación en las Mesas de Rentas y Colecturías, aunque tenía "el miedo a renovar las molestias ejercidas, y los justos clamores excitados por los viejos rematantes de los diezmos". ${ }^{79}$ Es en este sentido que la Cámara de Diputados, el 22 de septiembre de 1841, discutió la recaudación de impuestos en las provincias y sus dificultades. El diputado liberal Álvares Machado, recientemente salido de la presidencia de la Provincia de Rio Grande do Sul, dijo que, en aquellos tiempos, incluso después de los cambios legislativos iniciados en la década, los problemas relacionados con el personal de una administración directa permanecieron. En un gobierno representativo, el problema sería político y se derivaría de los intereses del partido involucrado. Para él, "el gobierno emplea a hombres en la administración hacendaria no por su probidad, no por su celo por la Hacienda, no por su capacidad, sino porque pertenecen a su partido". En las provincias se indicaban los nombres de los recaudadores, pero tales nombramientos, según el diputado, dependían principalmente de los resultados electorales y de la "máquina electoral". 80

Desde el punto de vista de la legislación, en la década de 1840, se emitieron algunas regulaciones que indican la supervivencia de los rematantes. El artículo 46 de la Ley del presupuesto núm. 317 del 21 de octubre de 1843 buscó limitar los plazos e imponer un valor mínimo a las subastas, de modo que el precio final no fuera inferior al $110 \%$ del ingreso anterior más alto de la renta adjudicada. La redacción del Decreto núm. 416 del 13 de junio de 1845 aclara una cierta preferencia por la subasta, "siempre que sea posible", de las ramas de la renta de las colecturías y órganos del gobierno. ${ }^{81}$ La indicación de que tal práctica debería observarse fuera de las capitales apunta a la dificultad de expandir la red de cobranza bajo administración directa, limitando la capilaridad fiscal del Estado. ${ }^{82}$

En el proprio ordenamiento de la administración hacendaria del Estado imperial presente en los reglamentos fundamentales del Tesoro Nacional y de los Tesoros Provinciales, establecidos en 1831 y 1850, se observa el espacio otorgado a los arrendamientos. De acuerdo con la Ley de 1831, ninguna adjudicación de contrato debía concluirse sin la aprobación del presidente del Consejo Provincial y, en el caso de la Corte y la provincia de Río de Janeiro, el Tribunal del

\footnotetext{
78 Barros, José Mauricio Fernandes Pereira de, Apontamentos de direito, 1855, p. 16.

79 Torres, Joaquim José Rodrigues, Proposta e relatorio, 1852, pp. 23-24.

80 Discurso de la asamblea legislativa de la Cámara de Diputados del 22 de septiembre de 1841 publicado en Jornal do Commercio, 25 de septiembre de 1841, núm. 244, p. 2.

81 Branco, Manuel Alves, Proposta e relatorio, 1845, p. 89.

82 Barros, José Mauricio Fernandes Pereira de, Apontamentos de direito, 1855, pp. 9-10.
} 
Tesoro. ${ }^{83}$ Este punto se repetiría en la reforma de $1850 .{ }^{84}$ También se reproduciría la posibilidad de renovar las subastas caso la adjudicación estuviera en desacuerdo con las leyes e instrucciones. ${ }^{85}$

Los únicos cambios observados desde 1850 se refieren a un mayor apoyo de la Dirección General del Contencioso, que debería redactar los términos de las subastas y garantías, atender las subastas de bienes, rentas o contratos que se hicieron en el Tesoro o por el Ministerio de Hacienda y supervisar la legalidad de estas subastas. ${ }^{86}$ Se observa que las subastas en las provincias no estaban cubiertas por la Dirección General del Contencioso. En este caso, estas funciones serían ejercidas por la sección de Contencioso y por el procurador fiscal, jefe de esa sección, presente en cada Tesoro de la Hacienda provincial. ${ }^{87}$

Así, observamos la conservación del sistema de arrendamiento por contratos, aunque en menor medida que la observada en el período colonial. De lo que se puede ver en un comentario de Amaro Cavalcanti, realizado en sus Elementos de Finanzas (1896), el sistema permaneció en las esferas provinciales y locales, especialmente en esta última. En las provincias, se arrendaban muchos tributos a cargo de las colecturías y de las mesas de rentas. En los municipios, era la forma preferida de recaudación. Como balance de las últimas décadas del estado imperial, Cavalcanti afirma que el uso del contrato de arrendamiento "se ha reducido cada vez más y, después de todo, totalmente abandonado", excepto en la cuestión de los bienes nacionales. ${ }^{88}$ Esta evaluación nos permite comprender cómo el avance de la administración directa a lo largo del período imperial se concentró en el gobierno central, especialmente en los ingresos obtenidos en la Corte en la tributación de los bienes importados y que constituían la mayor parte de los ingresos del Estado. En las provincias, ciudades y pueblos, no era necesario gastar una gran fuerza para reemplazar el sistema de arrendamiento, ni tampoco los costos de construir y mantener una extensa red de administración directa.

A su vez, la lenta construcción de una burocracia hacendaria en el siglo XIX estuvo rodeada de obstáculos. Antes de la reforma de 1834, "la voz pública denunciaba las aduanas como el emporio del fraude y de la prevaricación", declaraba el ministro de Hacienda Bernardo Pereira de Vasconcelos. La situación de recaudar otros ingresos no fue mejor: "Hubo rentas que no se recaudaron; otros, que se derretían a manos de recaudadores; muchos, que fueron malversados por diferentes fraudes; y no pocos devorados por las estratagemas de fuero". ${ }^{89}$

La falta de empleados suficientes, la remuneración de los funcionarios que no se mantuvieron al día con la inflación y la mala distribución de los recursos humanos entre las divisiones administrativas son aspectos presentados en los informes de los ministros de hacienda hasta mediados del siglo XIX. En 1852,

83 Ley de 4 de octubre de 1831, cap. II, art. 56.

84 Decreto núm. 736, 20 de noviembre de 1850, título V, art. 81.

85 Ibidem, título $\mathrm{V}$, art. 82.

86 Ibidem, título II, cap. VI, art. 24 e art. $26, \S 4^{\circ}$.

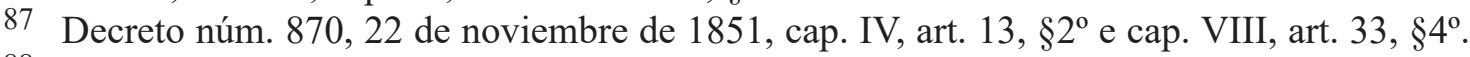

88 Cavalcanti, Amaro, Elementos de finanças, 1896, pp. 484-485.

89 Vasconcelos, Bernardo Pereira de, Relatorio, 1832, p. 25. 
cuando probablemente todavía no se hacían sentir los efectos de la reforma de 1850, el ministro Rodrigues Torres señaló las dificultades para obtener funcionarios correctos, siendo la regla general el desvío de parte de los recursos recaudados por los propios funcionarios:

La buena recaudación de impuestos, cuya recaudación pertenece a las oficinas de recibimiento, depende en gran medida de los lanzadores; y no siempre es posible encontrar personas para estos trabajos, quienes, sin una remuneración suficiente para asegurarles una existencia cómoda, someten otros sentimientos a la conciencia del deber, aunque menos nobles, tienen una poderosa influencia en las acciones humanas [...]. Las circunstancias de nuestro país, y los pequeños ingresos de la grande parte de las colecturías, no invitan a hombres que puedan manejarlos con celo y puntualidad para hacerse cargo de ellos. Por lo tanto, una gran parte de los impuestos ya no se recauda o desaparece, lo que es aún peor, de manos de los recaudadores. ${ }^{90}$

La reforma de la Tesorería Nacional y de las Tesorerías Provinciales en 1850/1851 permitió una inspección "más efectiva y rápida" y un "personal en general calificado e instruido", según el ministro de Hacienda, como se indica en el informe para el año $1856 .{ }^{91}$ Al igual que la Ley del 3 de octubre de 1831, que había creado el Tesoro Nacional y las Tesorerías, la reforma reafirmaba la obligación de tener en cuenta "todos los departamentos y personas responsables de recaudar y gastar dinero, o valores pertenecientes a la Nación", tanto en el plano imperial como provincial.

La mayor efectividad del control indicado en 1857 fue la posibilidad de suspensión, tal vez definitiva, de los responsables en ausencia de prestación de cuentas y documentos, mientras que la Ley de 1831 preveía solo la suspensión temporal. Si, incluso después de un nuevo plazo, no presentaron los documentos solicitados, podrían ser arrestados y tener sus bienes secuestrados. Así, correspondía al Tribunal del Tesoro Nacional pasar la aprobación de la gestión a los tesoreros, receptores, pagadores, almaceneros y otros funcionarios. ${ }^{92}$

Con respecto al funcionalismo, las reformas de 1831 y 1850 trajeron la novedad de acceso por concurso, en la que se exigía a los futuros empleados en las estaciones del Tesoro y en las tesorerías provinciales conocimiento de gramática, aritmética, cálculo mercantil y escrituración por partida doble, además de buena letra. Inicialmente el requisito de edad mínima era de 21 años, después se redujo a 18 años. Ciertamente, aquellos que tenían experiencia en actividades mercantiles salieron con una ventaja, ya que se requería, en la reforma de 1850 , saber cómo proceder "para reducir monedas, pesos y medidas, calcular descuentos, e intereses simples y compuestos", mientras que anteriormente solo se le exigía vagamente conocer el "cálculo mercantil".

90 Torres, Joaquim José Rodrigues, Proposta e relatorio, 1852, pp. 23-24.

91 Wanderley, João Mauricio, Proposta e relatorio, 1857, p. 7.

92 Ley del 4 de octubre de 1831, cap. II, art. 6, § 3 y cap. IV, art. 12, § 4; Decreto núm. 736, 20 de noviembre de 1850, título I, cap. I, artículo 2, §§ 3, 4 y 5; Decreto núm. 870, 20 de noviembre de 1850, cap. I, título I, artículo $1, \S \S 3,4$ y 5 . 
En algunos puntos, la reforma de 1850 puede considerarse más restrictiva que la ley anterior. Primero, incluyó una serie de excepciones para cargos mayores y menores en las estaciones fiscales. También exigió que los candidatos tuvieran experiencia como practicantes en la tesorería, dicho agente fue definido por Bluteau como aquel que "frecuenta este tribunal [de los Cuentos] para aprender sus estilos y prácticas". ${ }^{93}$ Finalmente, es extraño cómo podría ser evaluado el criterio bastante vago de "buen comportamiento", requerido por el concurso. ${ }^{94}$

\section{CONSIDERACIONES FINALES}

El presente capítulo buscó revisar, en sus líneas generales, la gran transformación de la administración hacendaria en Brasil a lo largo de un siglo, partiendo del arreglo absolutista del imperio colonial hasta el modelo forjado en el liberalismo constitucional del país independiente. Contrariamente a una visión inicial, que favoreció la idea de una continuidad entre el Erario Regio y el Tesoro Público, enfoque típico de la genealogía de la nación como el presentado por Tobias Rios (1908), nos damos cuenta de que hubo muchos conflictos y resistencias, todavía poco detallados por las interpretaciones que privilegian la uniformidad y el poder de la ley.

Además, ambos sistemas de administración hacendaria —el colonial absolutista y el liberal independiente- se construyeron sobre planes heterogéneos y temporalidades distintas. La cuestión de la heterogeneidad de los espacios administrativos no siempre se evalúa bien en los estudios sobre la historia de la administración fiscal. En general, tienden a enfocar el establecimiento del Erario Regio como un proceso automático, sin considerar, por ejemplo, los caminos tortuosos de formación de las Juntas de Hacienda en las partes del imperio. O tratan la creación de la Tesorería Nacional y las tesorerías provinciales como un resultado espontáneo de la ley de 1831. De esta forma, intentamos señalar los diferentes estratos que estructuraron la administración hacendaria, procesos ocurridos no siempre de manera conectada ni destituida de fricciones.

Otro aspecto que torna más compleja la historia de la administración hacendaria son sus diferentes temporalidades. Como se puede apreciar al largo del texto, los cambios en la cúspide de la administración central, que incluía instituciones como el Erario Regio, el Consejo de Hacienda o, más tarde, el Tesoro Nacional, ocurrieron mucho más rápidamente que los presentes en las bases del sistema, con la larga persistencia de los rematantes a nivel municipal y provincial. Así, recordando un poco las lecciones de Braudel, es necesario una historia de la administración hacendaria más atenta a los diferentes ritmos y las fuerzas de larga duración que estructuran las continuidades institucionales.

Finalmente, un tercer aspecto no menos importante es el vínculo político entre los diferentes proyectos del Estado y la elección de sistemas distintos de administración fiscal, con claras consecuencias para la construcción histórica

93 Bluteau, Raphael, Vocabulario portuguez, 1712-1728, vol. 6, p. 673.

94 Ley del 4 de octubre de 1831, título IV, art. 96, y Decreto núm. 736, título IV, cap. I, artículos 45 y 46. 
de las relaciones entre los intereses privados y los intereses del Estado, ya sea en su versión absolutista, en beneficio de la Corona, o en su versión liberal, en que podría prosperar el interés público. Este aspecto fue señalado tangencialmente por el análisis de los cambios en la idea de Real Hacienda y Tesoro Público presentados en la sección inicial del texto. De todos modos, el tema de la administración hacendaria está muy lejos de la neutralidad proclamada y cultivada por el propio discurso de la burocracia fiscal. Depende de los historiadores analizarlo como uno (o varios) discurso(s) de poder, incluyendo la idea de eficiencia en la recaudación tributaria, que han buscado legitimar, en sus diferentes contextos, la extracción y redistribución de recursos por parte del Estado.

\section{BIBLIOGRAFÍA}

\section{Archivos}

AHTC Archivo Histórico del Tribunal de Cuentas, Lisboa, Portugal ANRJ Archivo Nacional, Río de Janeiro, Brasil

\section{Hemerografía}

Jornal do Commercio, Río de Janeiro.

\section{Fuentes consultadas}

AIDAR, Bruno, "A reforma do Tesouro Nacional e os liberais moderados" en Gladys Sabina Ribeiro y Adriana Pereira Campos (coords.), Histórias sobre o Brasil no oitocentos, São Paulo, Alameda, 2016, pp. 13-36.

AIDAR, Bruno, "A vereda dos tratos: fiscalidade e poder regional na capitania de São Paulo, 1723-1808”, tesis doctoral en Historia Económica, São Paulo, Universidad de São Paulo, 2013.

AIDAR, Bruno, "Governar a Real Fazenda: composição e dinâmica da Junta da Fazenda de São Paulo, 1765-1808”, História Econômica \& História de Empresas, Asociación Brasileña de Investigadores en Historia Económica, vol. 16, núm. 2, 2013, São Paulo, pp. 163-217.

AIDAR, Bruno, "Uma substituição luminosa: tributação e reforma do Antigo Regime português em D. Rodrigo de Souza Coutinho ao final do século XVIII", Nova Economia, Departamento de Ciencias Económicas de la Universidad Federal de Minas Gerais, vol. 21, 2011, Belo Horizonte, pp. 137-156.

Almeida, Miguel Calmon du Pin e, Proposta e relatório da Reparticção dos Negocios da Fazenda apresentado á Assemblea Geral Legislativa na sessão ordinária de 1838 pelo respectivo Ministro e Secretario de Estado Miguel Calmon du Pin e Almeida, Río de Janeiro, Typographia Nacional, 1838.

Annaes do Parlamento. Camara dos Srs. Deputados. Terceiro anno da Primeira Legislatura. Sessão de 1828, Río de Janeiro, Typographia Parlamentar, 1876. 
Araúso, Luís Antônio Silva, "Em nome do rei e dos negócios: direitos e tributos régios nas minas setecentistas (1730-1789)", tesis doctoral en Historia, Niterói, Universidad Federal Fluminense, 2008.

Barcelos, Fábio Campos, A Secretaria de Estado dos Negócios da Fazenda e o Tesouro Nacional, Río de Janeiro, Arquivo Nacional, 2014.

Barros, José Mauricio Fernandes Pereira de, Apontamentos de direito financeiro brasileiro, Río de Janeiro, Eduardo \& Henrique Laemmert, 1855.

BALBI, Adrien, Essai statistique sur le royaume de Portugal et d'Algarve: comparé aux autres états de l'Europe, et suivi d'un coup d'œil sur l'état actuel des sciences, des lettres et des beaux-arts parmi les Portugais des deux hémisphères, Paris, Rey et Graviez, 1822, 2 vols.

Borges, José Ferreira, Principios de syntelologia: comprehendendo em geral a theoria do tributo, e em particular observaçoens sobre a administração, $e$ despezas de Portugal, em grande parte applicaveis ao Brazil, Londres, Binghan, 1831.

Borges, José Ignacio, Relatorio do ministro e secretorio d'Estado dos Negocios da Fazenda José Ignacio Borges na sessão de 1831, Río de Janeiro, Typographia de Gueffier e Ca., 1831.

Bluteau, Raphael, Vocabulario portuguez \& latino: aulico, anatomico, architectonico..., Coimbra, Collegio das Artes da Companhia de Jesu, 1712-1728, 8 vols.

Branco, Manuel Alves, Proposta e relatório do anno de 1844 apresentados a Assemblea Geral Legislativa na $2^{a}$ Sessão da $6^{a}$ legislatura pelo Ministro e Secretario d'Estado dos Negocios da Fazenda Manuel Alves Branco, Río de Janeiro, Typographia Nacional, 1845.

Collecção das leis do Imperio do Brasil de... Río de Janeiro, Typographia Nacional, 1822-1889.

Bueno, José Antonio Pimenta, Direito publico brazileiro e analyse da constituição do Imperio, Río de Janeiro, Typographia Imp. e Const. de J. Villeneuve e C., 1857, 2 vols.

Buescu, Mircea, Organização e administração do Ministério da Fazenda no império, Brasília, Fundação Centro de Formação do Servidor Público, 1984 (História administrativa do Brasil, 13).

CAmargo, Angelica Ricci, "Juntas da Real Fazenda", en Dicionário online da administração pública brasileira do período colonial (1500-1822), Río de Janeiro, Arquivo Nacional, 2013, <http://mapa.an.gov.br/index.php/dicionario-periodo-colonial/181-juntas-da-real-fazenda $>$. [Consulta: 19 de diciembre de 2018.].

CAmargo, Angelica Ricci, CABral, Dilma (coords.), Guia da administração brasileira: império e governo provisório (1822-1891), Río de Janeiro, Arquivo Nacional, 2017.

CARrara, Angelo, "A administração dos contratos da capitania de Minas: o contratador João Rodrigues de Macedo, 1775-1807”, América Latina en la Historia Económica, Instituto Mora, vol. 35, 2011, Ciudad de México, pp. 29-52. 
Cartas Andradinas. Correspondencia particular de José Bonifacio, Martim Francisco e Antonio Carlos dirigida a A. de M. Vasconcellos de Drummond, Rio de Janeiro, Typ. de G. Leuzinger \& Filhos, 1890.

Cavalcanti, Amaro, Elementos de finanças (estudo theorico-pratico), Rio de Janeiro, Imprensa Nacional, 1896.

Collecção dos decretos, resoluções e ordens das Cortes Gerais, Extraordinárias e Constituintes da Nação portuguesa desde a sua instalação em 26 de janeiro de 1821, Parte I, Coimbra, Imprensa da Universidade, 1822. Freire, Pascoal José de Melo. "Instituições de direito civil português: tanto público como particular", trad. Miguel Pinto de Meneses, Boletim do Ministério da Justiça, Ministério da Justiça de Portugal, vol. 168, 1967, Lisboa, pp. 27-165. (edicción original en latín, 1805).

Chaves, Cláudia, "Os poderes regionais e a construção política do espaço: as complexas jurisdições da administração fazendária no Brasil entre 18211823", Almanack, Universidad Federal de São Paulo, núm. 18, 2018, São Paulo, pp. 182-211.

Constitución política del Imperio de Brasil (1824).

Cruz, Miguel Dantas da, "Erário Régio", en E-dicionário da terra e do território no império português, Lisboa, Centro de Estudios de Historia Contemporánea, Instituto Universitario de Lisboa, 2014, <https://edittip.net/category/ erario-regio/>. [Consulta: 19 de diciembre de 2018.]

Cunha, Alexandre Mendes, "A Junta da Real Fazenda em Minas Gerais em seu diálogo com o Erário Régio", en Boschi, Caio César y Régis Clemente Quintão (coords.), Minas Gerais no Arquivo Histórico do Tribunal de Contas de Portugal, Belo Horizonte, Pontificia Universidad Católica de Minas Gerais, 2015, pp. 18-28.

ELLIS, Myriam, "Comerciantes e contratadores do passado colonial: uma hipótese de trabalho", Revista do Instituto de Estudos Brasileiros, Universidad de São Paulo, núm. 24, 1982, São Paulo, pp. 97-122.

FERNANDES, Valter Lenine, "Os contratadores e o contrato da dízima da Alfândega da cidade do Rio de Janeiro (1726-1743)", tesis de maestría, Río de Janeiro, Centro de Ciencias Humanas y Sociales, Universidad Federal del Estado de Río de Janeiro, 2010.

FigueIREDo, Luciano, "O Erário Régio: uma breve introdução", em Boschi, Caio César y Régis Clemente Quintão (coords.), Minas Gerais no Arquivo Histórico do Tribunal de Contas de Portugal, Belo Horizonte, Pontificia Universidad Católica de Minas Gerais, 2015, pp. 11-17.

GABLER, Louise, "Tesourarias das províncias" en Dicionário online da administração pública brasileira do período imperial (1822-1889), Río de Janeiro, Arquivo Nacional, 2016, <http://mapa.an.gov.br/index.php/menu-de-categorias-2/345-tesourarias-das-provincias-tesourarias-da-fazenda $>$. [Consulta en 19 de diciembre de 2018.].

Herculano, Alexandre, Opúsculos, 5a. ed., vol. 5, Río de Janeiro/ Lisboa, Livraria Bertrand/Livraria Francisco Alves. 
HesPanha, António Manuel, “A fazenda", en José Mattoso (dir.), História de Portugal, Lisboa, Editorial Estampa, 1998, vol. 4, pp. 181-213.

Hespanha, António Manuel, Às vésperas do Leviathan: instituições e poder político, Portugal (século XVII), Coimbra, Almedina, 1994.

Martins, Ana Canas Delgado, Governação e arquivos: D. João VI no Brasil, Lisboa, Instituto dos Arquivos Nacionais/Torre do Tombo, 2007.

MaIA, José Antônio da Silva, Compendio do direito financeiro, Río de Janeiro, Typographia Nacional, 1841.

Menz, Maximiliano, "Domingos Dias da Silva, o último contratador de Angola: a trajetória de um grande traficante de Lisboa", Tempo, Universidad Federal Fluminense, vol. 23, núm. 2, 2017, Niterói, pp. 383-407.

Miranda, Marcia Eckert, A estalagem e o império: crise do Antigo Regime, fiscalidade e fronteira na província de São Pedro (1808-1831), São Paulo, Aderaldo \& Rotschild, 2009.

Montesquieu, Charles Louis de Secondat, baron de Brède et de O espírito das leis, 2a. ed., Brasília, Editora da Universidade de Brasília, 1995.

Neves Neto, Raimundo Moreira, Em aumento de minha fazenda e do bem desses vassalos: a Coroa, a Fazenda Real e os contratadores na Amazônia colonial (séculos XVII e XVIII), Jundiaí, Paco Editorial, 2019.

O Conselho da Fazenda. Inventário e estudo institucional, Lisboa, Divisão de Publicações da Direção de Serviços de Arquivística e Inventário da Torre do Tombo, 1995.

Oliveira, Candido Baptista de, Systema financial do Brasil, San Petersburgo, Typographia Privilegiada de Fischer, 1842.

Online Etymology Dictionary, <http://www.etymonline.com/index.php>. [Consulta: 24 de agosto de 2017].

Pesavento, Fábio, y Guimarães, Carlos Gabriel, "Contratos e contratadores do Atlântico Sul na segunda metade do Setecentos", História, Histórias, Universidad de Brasília, vol. 1, núm. 1, 2013, Brasília, pp. 72-87.

PeDreira, Jorge, "Os homens de negócio da praça de Lisboa de Pombal ao vintismo (1755-1822): diferenciação, reprodução e identificação de um grupo social", tesis doctoral en Sociología, Lisboa, Universidad Nueva de Lisboa, 1995.

Petrone, Maria Thereza Schorer, O Barão de Iguape: um empresário da época da Independência, São Paulo, Companhia Editora Nacional, 1976.

Real Academia Española, Diccionario de la lengua castellana en que se explica el verdadero sentido de las voces, su naturaleza y calidad, con las phrases o modos de hablar, los proverbios o rephranes, y otras cosas convenientes al uso de la lengua, Madrid, Imprenta de Francisco del Hierro, 1726-1739, 6 vols.

RIBEIRO, Eder da Silva, "Nas tramas da política, nos bastidores das instituições: o Conselho da Fazenda e a construção do Império luso-brasileiro nos trópicos (1808-1821)", tesis doctoral, Niterói, Universidad Federal Fluminense, 2017. Rios, Tobias Candido, Thesouro Nacional. 1808-1908. Resumo histórico, Río de Janeiro, Imprensa Nacional, 1908. 
SANTOS, Iara Dias dos, "Os contratos dos dízimos da Bahia setecentista: economia, sociedade e fiscalidade (c.1724-c.1770)", tesis de maestría em historia económica, São Paulo, Universidade de São Paulo, 2018.

SAlgado, Graça (coord.), Fiscais e Meirinhos: a administração no Brasil Colonial, Rio de Janeiro, Nova Fronteira, 1985.

SousA, José Roberto Monteiro de Campos Coelho e, Systema, ou collecção dos regimentos reaes, contém os regimentos pertencentes á administraçaõ da Fazenda Real, Lisboa, Officina de Francisco Borges de Soisa, 1783-1791, 6 vols.

Silva, Antonio de Moraes, Diccionario da lingua portugueza recompilado dos vocabularios impressos ate agora, e nesta segunda edição novamente emendado e muito acrescentado, por Antonio de Moraes Silva, Lisboa, Typographia Lacerdina, 1813.

Subtil, José, "Governo e administração", en José Mattoso (dir.), História de Portugal, Lisboa, Círculo de Leitores, 1998, vol. 4, pp. 141-173.

Torres, Joaquim José Rodrigues, Proposta e relatorio apresentados á Assembléa Geral Legislativa na Quarta Sessão da Oitava Legislatura pelo Ministro e Secretario d'Estado dos Negocios da Fazenda Joaquim José Rodrigues Torres, Río de Janeiro, Typographia Nacional, 1852.

VAsConcelos, Bernardo Pereira de, "Carta aos senhores eleitores da Província de Minas Gerais" [1827] en José Murilo de Carvalho (coord.), Bernardo Pereira de Vasconcelos, São Paulo, Editora 34, 1999, pp. 58-191.

Vasconcelos, Bernardo Pereira de, "Parecer sobre o systema tributário" [1828], Revista do Archivo Publico Mineiro, Archivo Publico de Minas Gerais, vol. 8, 1903, Belo Horizonte, pp. 641-646.

VASCONCElos, Bernardo Pereira de, Relatorio apresentado á camara dos senhores deputados pelo ministro e secretario d'Estado dos Negocios da Fazenda Bernardo Pereira de Vasconcellos na sessão de 1832, Río de Janeiro, Typographia Nacional, 1832.

Viana, Candido José de Araújo, Relatório do Ministro Candido José de Araújo Viana apresentado a Assemblea Legislativa em 1832, Río de Janeiro, Typographia Nacional, 1833.

Viana, Vitor, Histórico da formação econômica do Brasil. Comemoração do $1^{o}$ centenário da independência do Brasil, Río de Janeiro, Imprensa Nacional, 1922.

Vilhosa, Francisco Luiz Teixeira, Brasil sede da monarquia. Brasil reinado $\left(2^{a}\right.$ parte), Brasília, FUNCEP, 1984 (História administrativa do Brasil, vol. 8, parte 2).

WANDERley, João Mauricio, Proposta e relatorio do Ministerio da Fazenda apresentados á Assemblea Geral Legislativa na primeira sessão da decima legislatura, Río de Janeiro, Typographia Nacional, 1857.

Esta obra está bajo licencia internacional Creative Commons ReconocimientoNo-Comercial-CompartirIgual 4.0.

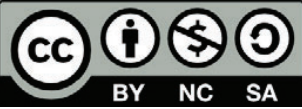

